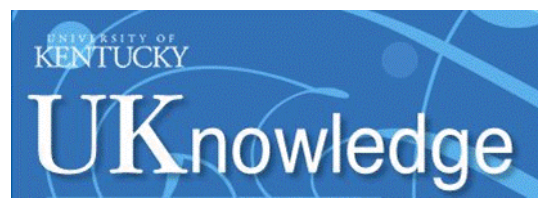

University of Kentucky

UKnowledge

\title{
4-2013
}

\section{Nutrition Intervention to Decrease Symptoms in Patients With Advanced Heart Failure}

\author{
Terry A. Lennie \\ University of Kentucky, terry.lennie@uky.edu \\ Debra K. Moser \\ University of Kentucky, debra.moser@uky.edu \\ Martha J. Biddle \\ University of Kentucky, mjbidd0@uky.edu \\ Darlene Welsh \\ University of Kentucky, jdwels00@uky.edu \\ Geza G. Bruckner \\ University of Kentucky, gbruckn@uky.edu
}

See next page for additional authors

Follow this and additional works at: https://uknowledge.uky.edu/nursing_facpub

Part of the Cardiology Commons, Dietetics and Clinical Nutrition Commons, and the Nursing

\section{Commons}

Right click to open a feedback form in a new tab to let us know how this document benefits you.

\section{Repository Citation}

Lennie, Terry A.; Moser, Debra K.; Biddle, Martha J.; Welsh, Darlene; Bruckner, Geza G.; Thomas, D. Travis; Rayens, Mary Kay; and Bailey, Alison L., "Nutrition Intervention to Decrease Symptoms in Patients With Advanced Heart Failure" (2013). Nursing Faculty Publications. 9.

https://uknowledge.uky.edu/nursing_facpub/9

This Article is brought to you for free and open access by the College of Nursing at UKnowledge. It has been accepted for inclusion in Nursing Faculty Publications by an authorized administrator of UKnowledge. For more information, please contact UKnowledge@lsv.uky.edu. 


\title{
Nutrition Intervention to Decrease Symptoms in Patients With Advanced Heart
}

\section{Failure}

\author{
Digital Object Identifier (DOI)
}

https://doi.org/10.1002/nur.21524

Notes/Citation Information

Published in Research in Nursing \& Health, v. 36, issue 2, p. 120-145.

Copyright @ 2013 Wiley Periodicals, Inc

This is the accepted version of the following article: Lennie, T. A., Moser, Debra. K., Biddle, M. J., Welsh, D., Bruckner, G. G., Thomas, D. T., Rayens, M. K. and Bailey, A. L. (2013), Nutrition intervention to decrease symptoms in patients with advanced heart failure. Research in Nursing \& Health, 36: 120-145, which has been published in final form at https://doi.org/10.1002/nur.21524. This article may be used for noncommercial purposes in accordance with Wiley Terms and Conditions for Self-Archiving.

Authors

Terry A. Lennie, Debra K. Moser, Martha J. Biddle, Darlene Welsh, Geza G. Bruckner, D. Travis Thomas, Mary Kay Rayens, and Alison L. Bailey 


\title{
Nutrition Intervention to Decrease Symptoms in Patients With Advanced Heart Failure
}

\author{
Terry A. Lennie ${ }^{1,{ }^{*}}$, Debra. K. Moser ${ }^{1,{ }^{*}}$, Martha J. Biddle ${ }^{1,{ }^{* *}}$, Darlene Welsh ${ }^{1,{ }^{* *}}$, Geza G.

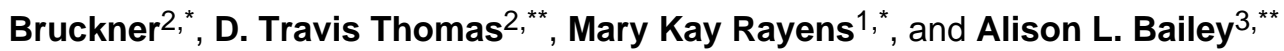 \\ ${ }^{1}$ College of Nursing, University of Kentucky, 751 Rose Street, Lexington, KY 40536-0232 \\ ${ }^{2}$ Division of Clinical Nutrition, Department of Clinical Sciences, College of Health Sciences, \\ University of Kentucky, Lexington, KY 40536-0232 \\ ${ }^{3}$ Division of Cardiovascular Medicine, College of Medicine, University of Kentucky, Lexington, KY \\ 40536-0232
}

\begin{abstract}
For a majority of patients with advanced heart failure, there is a need for complementary, nonpharmacologic interventions that could be easily implemented by health care providers to provide palliative care. Three major pathologic pathways underlying heart failure symptoms have been identified: fluid overload, inflammation, and oxidative stress. Prior research has demonstrated that three nutrients-sodium, omega-3 fatty acids, and lycopene-can alter these pathologic pathways. Therefore, the purposes of this study are to test the effects of a 6-month nutrition intervention of dietary sodium reduction combined with supplementation of lycopene and omega-3 fatty acids on heart failure symptoms, health-related quality of life, and time to heart failure rehospitalization or all-cause death. The aims of this double blind-placebo controlled study are (1) to determine the effects of a 6-month nutrition intervention on symptom burden (edema, shortness of air, and fatigue) and health-related quality of life at 3 and 6 months, and time to heart failure rehospitalization or all-cause death over 12 months from baseline; (2) compare dietary sodium intake, inflammation, and markers of oxidative stress between the nutrition intervention group and a placebo group at 3 and 6 months; and (3) compare body weight, serum lycopene, and erythrocyte omega- 3 index between the nutrition intervention group and a placebo group at 3 and 6 months. A total of 175 patients with advanced heart failure will be randomized to either the nutrition intervention or placebo group.
\end{abstract}

\section{Keywords}

heart failure symptoms; nutrition; omega-3 fatty acids; lycopene; sodium restriction

\footnotetext{
(C) 2013 Wiley Periodicals, Inc.

Correspondence to Terry A. Lennie.

***ofessor.

***Assistant Professor.
} 


\section{Editor's Note}

In 1990, RINAH published an example of a successful R01 grant proposal to NINR and excerpted critiques (Naylor, 1990). The application and review process has evolved since that time, so we are pleased to present a successful proposal submitted and reviewed in the current NIH application format, accompanied by NIH reviewer critiques. Submitted in response to a call for proposals on advanced heart failure and palliative care, and funded by NINR on its initial submission, this proposal is presented here with minimal editing. The summary, scores, and overall impact statements of the study section critiques follow the proposal, again with any errors or inconsistencies left intact. This article was handled as an editorial and not peer reviewed by the journal. We are grateful to Dr. Lennie and colleagues for sharing this work.

\section{Specific Aims}

The proposed study is in response to NIH Funding Opportunity RFA-11-006 Increasing Opportunities in Advanced Heart Failure and Palliative Care Research. The study addresses the following research initiative area of interest: Examine the impact of interventions on symptom management with attention to symptom severity. Heart failure ranks among the most costly health problems in terms of human suffering and health care expenditures (Lloyd-Jones et al., 2010). It is a syndrome in which symptoms define the diagnosis, severity, and determination of treatment effectiveness (Lindenfeld et al., 2010). Thus, HF is considered a symptom-driven syndrome. Although privilege major advances in medical management of HF over the past two decades have prolonged survival, patients with advanced HF remain symptomatic after optimization of medical treatment (Hunt et al., 2009). These symptoms are associated with frequent rehospitalizations and decreased health-related quality of life (Heo, Moser, Lennie, Zambroski, \& Chung, 2007). Current guidelines call for symptomatic relief and palliative care to be incorporated into the ongoing plan of care soon after diagnosis (Hunt et al., 2009). Combined, these observations indicate the need for non-pharmacological interventions to decrease symptom severity and improve quality of life that could be implemented as part of palliative care for patients with HF. We developed a low cost, nutrition intervention to decrease the severity of the three most common HF symptoms associated with frequent hospitalization and poor quality of life: fluid overload/edema, shortness of air, and fatigue (Lindenfeld et al., 2010). The intervention involves three nutrients that target the pathologic pathways underlying these HF symptoms: sodium, omega-3 fatty acids, and lycopene.

Excess sodium intake is associated with fluid overload symptoms of edema and shortness of air (Bennett et al., 1998; Chin \& Goldman, 1997; Happ, Naylor, \& Roe-Prior, 1997; Hoskins, Walton-Moss, Clark, Schroeder, \& Thiel, 1999; Michalsen, Konig, \& Thimme, 1998; Opasich et al., 1996; Tsuyuki et al., 2001; Vinson, Rich, Sperry, Shah, \& McNamara, 1990). We demonstrated that patients with advanced HF who consume higher $(>3 \mathrm{~g})$ sodium diets have 2.5 times greater risk of rehospitalization than similar patients consuming lower sodium diets (Lennie et al., 2011). Omega-3 fatty acids have beneficial anti-inflammatory and anti-dysrhythmic effects (Tavazzi et al., 2008). We have shown that diets low in omega-3 fatty acids in patients with HF are associated with high levels of the 
proinflammatory mediators (Lennie, Chung, Habash, \& Moser, 2005) linked with symptoms of fatigue and anorexia and altered myocardial and vascular endothelial function (Conraads, Bosmans, \& Vrints, 2002; Dantzer, 2009). Lycopene is a potent antioxidant (L. G. Rao, Guns, \& Rao, 2003) that plays a protective role against oxidative stress common in patients with HF (Anker et al., 2003). Oxidative stress stimulates inflammation and impairs vascular endothelial function leading to symptoms of edema, shortness of air, and fatigue (Doehner \& Anker, 2005). We have shown that diets of patients with HF low in lycopene are associated with greater risk of hospitalization than diets higher in carotenoids, particularly lycopene (Biddle et al., 2008).

To date, each of these nutrients has been individually demonstrated to have beneficial effects. However, there is sound theoretical rationale (Fig. 1) that a combined intervention targeting all three nutrients would have substantial benefit in relieving symptoms in advanced HF. Therefore, the purposes of this study are to test the effects of a 6-month nutrition intervention of dietary sodium reduction combined with supplemention of lycopene and omega-3 fatty acids on HF symptoms, health-related quality of life, and time to HF rehospitalization or all-cause death. Patients with advanced HF will be randomized to intervention or placebo group and blinded to the group to which they are assigned. The specific aims of this randomized, controlled, blinded trial are to:

1. Determine the effects of a 6-month nutrition intervention on symptom burden (i.e., edema, shortness of air, fatigue), health-related quality of life, and time to HF rehospitalization or all-cause death over 12 months.

Hypothesis 1a: Symptom burden will be lower, and health related quality of life will be higher in the nutrition intervention group than in the placebo group at month 3 and 6 during the intervention and at 9 and 12 months ( 3 and 6 months after the intervention).

Hypothesis 1b: Time to first event (HF rehospitalization or all-cause death) will be longer in the nutrition intervention group than in the placebo group at the 12-month time point.

2. Compare dietary sodium intake, markers of oxidative stress, and proinflammatory/ anti-inflammatory cytokine levels of patients in the nutrition intervention group with those of patients in the placebo group at 3-and 6-month time points.

Hypothesis 2a: Dietary sodium intake (reflected by 24-hour urine sodium) will be lower in the nutrition intervention than placebo group at the 3- and 6-month time points.

Hypothesis 2b: Serum markers of oxidative stress (malondialdehyde and 8-isoPGF2a isoprostane) will be lower in the nutrition intervention than placebo group at the 3-and 6-month time points.

Hypothesis 2c: Serum levels of proinflammatory markers (tumor necrosis factor-a [TNF] and soluble TNF receptors: sTNFR1, and sTNFR2) will be lower and antiinflammatory cytokine interleukin-10 will be higher in the nutrition intervention than placebo group at the 3- and 6-month time points. 
3. Compare the following markers of intervention adherence, fluid balance (body weight), serum lycopene, and erythrocyte omega-3 index, at 3- and 6-month time points between intervention and placebo groups.

Hypothesis 3. Intervention group will have stable body weights and higher serum lycopene levels and erythrocyte omega-3 index than placebo group at 3- and 6month time points.

\section{A. Significance}

\section{A1. Conceptual Framework}

Figure 1 is the conceptual framework guiding our intervention. The proposed intervention targets three major pathways underlying HF symptoms: fluid overload (depicted by short dashed lines), oxidative stress (dotted lines), and inflammation (long dashed lines). The symptoms produced by these pathways (solid lines) are primary reasons for HF (Heo et al., 2007; Hunt et al., 2009). Fluid overload, the best known of the three pathways, is due to compensatory neuroendocrine responses to decreased cardiac output that cause sodium and fluid retention (Hunt et al., 2009). Consequently, limiting sodium in the diet has been a mainstay of HF management for more than 60 years (Lennie, 2006). In the absence of diet instruction and skill building, patients are not successful in implementing sodium-restricted diets (Riegel et al., 2009). Our intervention is designed to provide patients with the knowledge and skills needed to effectively limit dietary sodium. In the second pathway, production of free oxygen radicals in response to hypoxia has two consequences (Doehner \& Anker, 2005). First, free radicals interact with nitric oxide (which plays a key role in vasodilation) to produce cell damaging oxidants (Doehner \& Anker, 2005). The subsequent loss of nitric oxide bioavailability in vascular endothelium results in increased vascular resistance, increased myocardial workload, and decreased cardiac output. Second, increased free oxygen radical production can exceed the antioxidant capacity of cells (oxidative stress), resulting in cellular damage that triggers inflammatory pathways (Anker et al., 2003). The lycopene supplementation in the proposed intervention will enhance cell antioxidant capacity thereby preserving endothelial nitric oxide, decreasing cell damage, and minimizing stimulation of inflammatory pathways. The third pathway involves proinflammatory cytokines which are elevated advanced HF (Conraads et al., 2002). These cytokines cause myocardial dysfunction and myocyte apoptosis resulting in decreased cardiac output (Ceconi, Curello, Bachetti, Corti, \& Ferrari, 1998). Proinflammatory cytokines also have systemic effects including decreased appetite and fatigue (Lennie, 1999). The omega-3 fatty acid supplementation component of the intervention targets the inflammation pathway. Increasing omega-3 fatty acid content in cell membranes reduces production of inflammatory mediators. In the myocardium, omega- 3 fatty acids produce the added benefit of decreasing cardiac dysrhythmias (Tavazzi et al., 2008).

\section{A1.1. Heart Failure Symptoms, Quality of Life, Hospitalization, and Survival-} Heart failure is a clinical syndrome characterized by a constellation of signs and symptoms (Hunt et al., 2009; Lindenfeld et al., 2010). Although medical treatment is aimed at reversing neurohormone and other pathologic responses to decreased cardiac output, the major target of treatment is HF symptom reduction (Hunt et al., 2009; Lindenfeld et al., 
2010). The decision to add or adjust medications is commonly guided by persistence or worsening of symptoms (Lindenfeld et al., 2010). Heart failure symptoms also drive decisions regarding rehospitalization and discharge once hospitalized (Dickstein et al., 2008). Data suggest that, after optimization of medications, 50\% (Lee et al., 2009; Lennie et al., 2011) to 85\% (Jurgens et al., 2009) of patients with HF remain in New York Heart Association (Lindenfeld et al., 2010; NYHA) functional Class III (experience symptoms with less than ordinary activity) or Class IV (experience symptoms at rest). Dr. Moser and colleagues have shown that unrelieved symptoms impact quality of life. Using the Memorial Symptom Assessment Scale-Heart Failure and the Minnesota Living with Heart Failure Questionnaire, they measured total symptom burden and quality of life of patients with HF, respectively (Zambroski, Moser, Bhat, \& Ziegler, 2005). The two symptoms with the highest prevalence $(85 \%)$ and greatest burden score (frequency + severity + distress) were lack of energy and shortness of air. The strongest predictor of quality of life was symptom burden, accounting for $22 \%$ of the variance. In other work, Moser and colleagues (Heo, Doering, Widener, \& Moser, 2008) reported comparable results when focusing only on physical symptoms. Most patients reported experiencing symptoms of fatigue and shortness of air daily. Similarly, physical symptoms were the strongest predictor of quality of life. In summary, symptoms drive the diagnosis and treatment of HF.

For a majority of patients, medical treatment is only partially effective in relieving symptoms. Unrelieved symptoms are related to low quality of life which, in turn, is a predictor of both hospitalization and survival (Alla et al., 2002; Moser et al., 2009). There is a clear need for complementary, non-pharmacologic, interventions that could be easily included in palliative care to decrease symptoms in patients with advanced HF.

\section{A2. Symptoms and Nutrition}

There is evidence that nutrition could play a crucial role in influencing symptoms and HF outcomes (Lennie, 2006; Lennie et al., 2005; Silver, 2003). Three nutrients, sodium, lycopene, and omega-3 fatty acids, have been identified as having the potential to the three major pathologic pathways, sodium/fluid retention, oxidative stress, and inflammation (Fig. 1).

A2.1. Fluid retention and sodium-Heart failure triggers a compensatory neurohormone response that includes release of aldosterone, angiotensin, and vasopressin (antidiuretic hormone), which cause sodium and fluid retention resulting in symptoms of fluid overload (Lindenfeld et al., 2010). Excess sodium intake has been implicated in a number of studies (Bennett et al., 1998; Chin \& Goldman, 1997; Happ et al., 1997; Hoskins et al., 1999; Michalsen et al., 1998; Opasich et al., 1996; Tsuyuki et al., 2001; Vinson et al., 1990) to be the precipitating factor for the majority of hospital admissions due to symptoms of decompensated HF. Several medications prescribed to patients with HF are aimed at blocking neuroendocrine responses to normalize sodium balance and decrease fluid retention (Hunt et al., 2009). Data from our recent study suggest that these drugs may not be sufficiently effective in patients with advanced HF to prevent rehospitalization (Lennie et al., 2011), making dietary sodium restriction necessary (J. Arcand et al., 2011). However, most patients with HF state they do not know the best methods for limiting sodium in the 
diet (Chung, Lennie, Worral-Carter, Bentley, \& Moser, 2004; Moser, Doering, \& Chung, 2005) and need additional information from health care providers regarding how to follow a low sodium diet (Bentley, De Jong, Moser, \& Peden, 2005; Sheahan \& Fields, 2008). This information may be most effective if provided in the context of the patient's typical eating habits (Welsh et al., 2010). Providing individual patient teaching based on assessment of patient's usual dietary patterns in addition to written instructions has been demonstrated to improve the ability to follow a low sodium diet (J. A. Arcand et al., 2005).

\section{A2.2. Inflammation and omega-3 fatty acids}

Inflammation: Heart failure is now conceptualized as a multi-system syndrome in which systemic inflammation is a major pathologic process (Conraads et al., 2002). Proinflammatory cytokines have pleotropic actions that directly or indirectly elicit many pathologic pathways underlying HF including activation of neurohormones, catabolism of body tissues, sodium and water retention, and impairment of ventricular function (Hedayat, Mahmoudi, Rose, \& Rezaei, 2010; Mann, 2004). Cytokines are also implicated in a group of inflammation-induced symptoms collectively called sickness behaviors (Dantzer, 2009). These sickness behaviors include malaise, fatigue, decreased socialization, and decreased appetite. Thus, decreasing the proinflammatory cytokine response is an attractive target for improving HF symptoms. Accordingly, three anti-TNFa clinical trials were conducted. Two were trials of etanercept, a TNF inhibitor, and one was a trial of infliximab, an anti-TNF antibody. Unfortunately, none of the trials showed any benefit; in fact treatment may have increased mortality (Heymans et al., 2009). Both drugs are global blockers of TNFa activity. Given that TNFa has immune-regulatory and other regulatory activities, low levels of TNFa activity may be necessary for normal function (Dantzer, 2009). Interventions, such as omega-3 fatty acid supplementation, that alter inflammatory pathways which stimulate release of pathologic levels of $\mathrm{TNFa}$ provide a viable alternative.

Omega-3 fatty acids: Omega- 6 and omega- 3 are essential fatty acids, meaning they must be derived from the diet. They play important roles in mediating cellular inflammatory responses. Tissue injury or stress trigger metabolic pathways that convert these fatty acids into the biologically active metabolites. Omega- 6 fatty acids form arachodonic acid metabolites such as prostaglandins $\mathrm{PGE}_{2}$, thromboxane $\mathrm{TXA}_{2}$, and leukotrienes $\mathrm{LTB}_{4}$ and $\mathrm{LTC}_{4}$. These metabolites are potent mediators of inflammation and promote vasoconstriction as well as platelet aggregation (Heller, Theilen, \& Koch, 2003). In addition, $\mathrm{PGE}_{2}$ plays a role in cytokine-induced sickness behavior by serving as a brain mediator for effects of peripherally produced cytokines (Dantzer, 2009). In contrast, the omega-3 fatty acids eicosahexaenoic acid (EPA) and docosahexaenoic acid (DHA) produce less inflammatory metabolites such as $\mathrm{PGE}_{3}$, and $\mathrm{PGI}_{3}$, thrombaxane $\mathrm{TXA}_{3}$, and leukotrienes $\mathrm{LTB}_{5}$ and $\mathrm{LTC}_{5}$. These metabolites suppress platelet aggregation, promote vasoconstriction, and do not mediate cytokine-induced sickness behaviors. Omega- 6 and omega- 3 fatty acids compete for the same enzymes during the process of forming their respective metabolites. Consequently, tissues with higher amounts of omega- 3 fatty acids produce less inflammation than tissues with more omega-6 fatty acids (Heller et al., 2003). As shown in Preliminary Data to Support the Intervention Section, most patients with HF are not likely to achieve an adequate level of dietary EPA and DHA. The omega-3 index has been 
recommended as a way to quantify the proportion of omega-3 fatty acids in cell membranes and can be used to determine adequacy of omega-3 fatty acid intake. It is defined as the amount of EPA plus DHA in erythrocyte cell membranes expressed as a percentage of total membrane fatty acids (Harris \& Von Schacky, 2004). An omega-3 index of $>4 \%$ is associated with a significant decrease in risk of sudden cardiac death (Harris, 2008). Eight weeks of supplementation with $1 \mathrm{~g}$ of EPA/DHA per day for 8 weeks results in an omega-3 index of $6.4 \%$ (Zhao et al., 2009).

\section{A2.3. Oxidative stress and lycopene}

Oxidative stress: Oxidative stress, defined as oxygen-free radical production that exceeds cellular antioxidant capacity, is associated with hospital readmission for exacerbation of HF symptoms (Rogowski, Shnizer, Wolff, Lewis, \& Amir, 2011). Hypoxia resulting from impaired cardiac output is proposed to increase the production of uric acid via stimulation of the enzyme xanthine oxidase (Doehner \& Anker, 2005). An important consequence of this pathway is the production of free oxygen radicals. When production of free oxygen radicals exceeds the antioxidant capacity of the cell, excess free oxygen radicals interact with functional cellular metabolites including nitric oxide, which maintains vascular tone (Doehner \& Anker, 2005). Loss of nitric oxide increases vascular resistance further impairing cardiac output and worsening HF symptoms (Doehner \& Anker, 2005; Rogowski et al., 2011). In this respect, uric acid can be used as a marker of oxidative stress (Anker et al., 2003). Lipid peroxidation is another consequence of excess oxygen-free radicals. In this pathway, free radicals remove electrons from polyunsaturated fatty acids in cell membranes altering cell membrane function. Cellular damage from oxidative stress in turn can stimulate inflammation (Anker et al., 2003). Plasma levels of malondialdehyde (MDA) and 8-isoPGF2a isoprostane are markers of lipid peroxidation (Polidori et al., 2002). Higher levels of these oxidative stress markers have been associated with lower levels of antioxidants, particularly lycopene, and more impaired cardiac output in patients with severe HF (Polidori et al., 2002, 2004). This indicates the need to increase the anti-oxidant capacity of patients with advanced HF. Providing additional dietary sources of anti-oxidants is a simple way to improve antioxidant status.

Lycopene: Lycopene is among the most abundant of dietary carotenoids that function as antioxidants (Pennathur et al., 2012; Shi \& Le Maguer, 2000a,b; Young \& Lowe, 2001). It is considered one of the most potent antioxidants; capable of limiting cellular damage from excess oxygen-free radical production (Basu \& Imrhan, 2007). Levels of lycopene in the body have been shown to increase with respect to the amount of lycopene in the diet (Basu \& Imrhan, 2007). This indicates that lycopene levels are sensitive to dietary intervention. Approximately $80 \%$ of the lycopene consumed in the United States comes from processed tomato products (Clinton, 1998). The best sources of dietary lycopene are tomato-based pasta sauces, tomato soup, canned tomatoes, tomato sauce, tomato paste, and tomato or tomato-based juices (Clinton, 1998). A wide range of dietary lycopene supplements (5.7-40 $\mathrm{mg}$ ) have been tested with evidence of antioxidant effects at each level (Basu \& Imrhan, 2007). Although supplements as low as $5.7 \mathrm{mg}$ have demonstrated antioxidant effects, the evidence was from healthy volunteers without oxidative stress. Higher levels are likely needed for those with oxidative stress. However, the data suggest that dietary 
supplementation need not exceed 20-25 mg to be effective in reducing oxidative stress (A. V. Rao, Ray, \& Rao, 2006).

\section{A3. Preliminary Data to Support the Intervention}

\section{A3.1. Data from BMI, nutrition, inflammation, and heart failure outcomes R01NR009280; T. A. Lennie, PI-A total of $248 \mathrm{HF}$ patients completed 4-day food} diaries. Because food intake has been shown to differ on weekends versus weekdays, food diaries were recorded Sunday (Day 1) through Wednesday (Day 4). The food diaries were reviewed by dietitians and analyzed with Nutrition Data Systems for Research software. During the diary recording period, patients completed Memorial Symptom Assessment Scale-Heart Failure for symptom measurement and Minnesota Living with HF questionnaire for measurement of quality of life. To demonstrate the effects of symptoms on quality of life, scores on Minnesota Living with HF are compared in Table 1 between patients in whom the symptoms of edema, fatigue, or shortness were present versus absent during the prior 7 days. Quality of life was worse in patients who reported edema $\left(t_{262}=5.6\right.$, $p<.001)$, fatigue $\left(t_{261}=10.6, p<.001\right)$, or shortness of air $\left(t_{261}=7.6, p<.001\right)$ was present during the prior 7 days.

To demonstrate effectiveness of the proposed intervention on symptoms, patients were dichotomized according to dietary sodium intake above and below $3 \mathrm{~g}$; lycopene intake above and below group median intake of 2,235 mg; omega- 3 intake above and below group median intake of $1.6 \mathrm{~g}$. Patients were then grouped according to quality of diet: Worst diet $=$ sodium intake above $3 \mathrm{~g}$ and both lycopene and omega-3 intake below median. Best diet $=$ sodium intake below $3 \mathrm{~g}$ and both lycopene and omega- 3 intake above the median. Poor diet $=$ having one component meeting best criteria. Table 2 shows a comparison of the frequency of reported edema, fatigue, and shortness of air among the four diet quality groups. Good diet $=$ having two components meeting best criteria. Fewer patients in the Best diet group reported having symptoms of fatigue $\left(\chi^{2}=11, p=.01\right)$ and shortness of air $\left(\chi^{2}=10, p=\right.$. $018)$. Given that quality of life was lower in patients with symptoms and that symptoms were more common in patients with lower quality diets, we tested whether quality of life was lower in patients with low quality diets. Table 3 shows a comparison of quality of life scores among the four diet quality groups. Patients in the Worst diet group had significantly poorer quality of life scores than patients in the Best diet group by one way ANOVA $\left(F_{3,244}\right.$ $=2.2, p<.02)$ with LSD post hoc tests.

It should be noted that the Best diet group contained the smallest number of patients indicating that most patients did not spontaneously achieve the dietary levels of all three nutrients that would be beneficial for decreasing symptoms and improving quality of life. Combined these results provide evidence of both the need for and potential effectiveness of our proposed nutrition intervention on symptoms and quality of life.

A3.2. Evidence for dietary sodium reduction component-The proposed dietary sodium reduction component was pilot tested in a randomized, repeated measures clinical trial by co-investigator Dr. Welsh (Welsh et al., 2012). Fifty-two patients with heart failure were randomized to either the intervention group $(n=27)$ or usual care $(n=25)$ group. The 
mean daily sodium intake was not significantly different between the intervention $(2,880 \pm$ $1,489 \mathrm{mg})$ and usual care $(3,070 \pm 1,352 \mathrm{mg})$ groups at baseline $\left(t_{47}=0.46, p=.64\right)$.

Analysis of covariance with baseline sodium intake as a covariate revealed that dietary sodium intake was significantly lower in the intervention group $(2,262 \pm 925 \mathrm{mg})$ than usual care $(3,164 \pm 886 \mathrm{mg})$ at 6 months $(p=.01)$.

A3.3. Evidence for lycopene supplementation component-The lycopene component was pilot tested in a randomized, controlled clinical trial headed by coinvestigator Dr. Biddle (under review). Twenty-two patients with HF randomized to an intervention of V-8 juice (11.5 oz/day; $25 \mathrm{mg}$ lycopene) for 3 months were compared to a usual care group of 18 patients. Four 24-hour diet recalls were obtained on random days over a 3-week period to determine dietary lycopene intake and blood was drawn for lycopene at baseline and 3 months. Serum lycopene levels were comparable between groups at baseline. Levels increased markedly at 3 months in the intervention group but were unchanged in the usual care group [statistics in original proposal were deleted here because results are in review elsewhere (Biddle et al., in review)]. The intervention was easily implemented, well tolerated by patients, and had a $100 \%$ adherence rate.

\section{A3.4. Evidence for omega-3 supplementation component-We previously} demonstrated that higher dietary intake of omega-3 fatty acids is associated with lower plasma levels of the inflammatory markers: soluble TNF receptors sTNF-R1 and sTNF-R2 (Lennie et al., 2005). Patients who consumed $>1.2 \mathrm{~g}$ of omega- 3 fatty acids had significantly lower levels of sTNF-R1 than patients who consumed $<1.2 \mathrm{~g}$ of omega- 3 fatty acids $(2,323$ $+1,034$ vs. $3,307 \pm 1,973 \mathrm{pg} / \mathrm{ml}$; respectively). The same was true for sTNFR2 $(4,114 \pm$ 2,646 vs. $5,409 \pm 2,801$, respectively). The GISSI-HF trial provides strong evidence for the safety, efficacy, and tolerability of the proposed omega-3 supplementation. Nearly 3,500 patients with HF were randomized to receive $1 \mathrm{~g}$ of omega-3 fatty acids/day for a median of 3 years (Tavazzi et al., 2008). Omega-3 supplementation was well tolerated and did not produce adverse effects in patients with HF. The treatment resulted in a modest decrease in all cause hospitalization and death. Support for the effectiveness of omega-3 fatty acid supplementation in lowering inflammation is found in a placebo controlled study of 75 patients with HF (38 omega-3 vs. 37 placebo; Zhao et al., 2009). Omega-3 supplementation of $300 \mathrm{mg}$ EPA/DHA/day for 3 months resulted in a $25 \%$ reduction in plasma TNFa levels in the omega-3 supplementation group compared with no change in the placebo group.

\section{B. Innovation}

Palliative care is indicated for patients with incurable conditions in which medical treatment is no longer effective in managing symptoms. In these cases, complementary interventions for symptom management that can be easily implemented by health care providers for patients low physical reserve and limited financial resources are needed. The proposed study is a test of a novel low cost intervention requiring minimal patient effort that is designed to be carried out as part of routine home visits. It is the first combined intervention that targets three nutrients which individually have been shown to affect pathologic pathways underlying symptoms of HF. It will be the first study to control for dietary intake of other nutrients that could alter or mask the effects of the intervention. This will also be the first 
study to measure whether the intervention achieves the desired changes levels of inflammatory mediators, markers of oxidative stress, and body fluid.

\section{Approach}

\section{C1. Design}

The proposed randomized, placebo-controlled nutrition intervention study is a two-group, prospective design (nutrition intervention vs. placebo) in which HF symptoms, healthrelated quality of life, and serum levels of proinflammatory cytokines and markers of oxidative stress are measured at baseline and Months 3 and 6 of the intervention. Patients will be blind to group assignment however it is not possible to blind interventionists. Data on HF symptoms and health-related quality of life will also be collected at 9 and 12 months from baseline. Data on patient hospitalization and death (time to first event) will be collected monthly for 12 months from baseline. Sociodemographic, clinical, and other variables that can affect study outcomes will be collected at baseline and are: body weight, height, medications, and depressive symptoms. The following biological markers of adherence to the nutrition intervention will be collected at baseline, 3-, and 6-month time points: erythrocyte omega-3 index, serum lycopene levels, and dietary sodium intake. The following biological indicators of intervention effects on pathologic pathways underlying symptoms will be collected at baseline, 3-, and 6-month time points: fluid status (body weight), oxidative stress (malondialdehyde, uric acid, and 8-iso-PGF2a isoprostane), and cytokine (TNFa, sTNF receptors, and IL-10) levels. The protocol is designed to minimize subject burden by limiting the number of questionnaires to be completed and collecting data in patient homes unless an alternative site is preferred.

Rationale for $\mathbf{2}$ group design-A typical approach to this type of study would be to use a 4 or 5 group design in which each component of the intervention is tested separately and compared to the combined intervention. However, each component of the intervention has already been demonstrated to have beneficial effects. We are not hypothesizing that any one component of the intervention is more effective than others, but rather that the combined intervention is novel. Moreover, Figure 1 demonstrates the interactive nature of the pathologic pathways underlying HF symptoms and illustrates the importance of providing an intervention that concurrently targets all three pathways. Each of these pathways, if untreated, could trigger responses that would diminish the effectiveness of an intervention aimed at treating one of the other single pathways. Thus, any test of a single nutrition component would require that we control or account in some way for the effects of the other components. This is most effectively accomplished by providing the proposed combined intervention.

Sample and setting -A total of 150 patients (75 per group) will be assigned to groups by stratified (by gender) random assignment. Based on an estimated attrition of $25 \%$ derived from previous studies, we have planned and budgeted for recruitment of 200 patients. Attrition by mortality is an outcome so it does not reduce the sample. University of Kentucky (UK) Chandler Medical Center will serve as the recruitment site. The UK Chandler Medical Center is a regional tertiary care referral facility and is the largest 
academic medical center in Kentucky. In a recent study, our research team recruited $37 \mathrm{HF}$ patients (mean age $61 \pm 15$ years; $48 \%$ female, $84 \%$ Caucasian, $14 \%$ African-American, $2 \%$ Hispanic) for a complex, longitudinal project in less than a month. Despite the fact that HF is equally distributed between the genders, the representation of women in many studies of HF has been poor. In order to represent women in this study we will enroll 50\% women. The population of HF patients at all UK Chandler Medical Center clinical sites is approximately $50 \%$ women so we do not anticipate problems in obtaining an adequate sample of women for this study. This coupled with our experience in two studies (one of 90 [45\% women; 22\% African-American] HF patients and another in 135 patients [52\% women; 28\% African American]) recruited from a HF service and from local community hospitals demonstrates our ability to recruit women and minorities.

Inclusion/exclusion criteria-Patents recruited will have a diagnosis of chronic HF with either preserved or non-preserved ejection fraction. This is the population enrolled in all of our preliminary studies and interventions have been equally effective in both groups. The diagnosis and etiology of chronic HF will be confirmed by a HF cardiologist using established criteria (Hunt et al., 2009; Packer, Cohn, \& on behalf of the Steering Committee and Membership of the Advisory Council to Improve Outcomes Nationwide in Heart Failure, 1999). Other inclusion criteria are: (a) have undergone evaluation of HF and optimization of medical therapy, (b) NYHA functional classification of III or IV (advanced $\mathrm{HF}$ ), (c) have not been referred for heart transplantation, (d) able to read and speak English, and (e) no cognitive impairment that precludes giving informed consent or ability to follow protocol instructions. Patients will be excluded if they have: (a) BMI $<17$ or $>45 \mathrm{~kg} / \mathrm{m}^{2}$ (Fontaine, Redden, Wang, Westfall, \& Allison, 2003; Wilson \& Morley, 1999) (b) valvular heart disease as the etiology of HF, (c) myocardial infarction within prior 3 months, (d) uncontrolled diabetes mellitus ( $\mathrm{HgA} 1 \mathrm{c}>8 \%$ ), (e) co-existing illness known to be associated with systemic inflammation, decreased appetite, fatigue, edema, or weight loss, or (f) currently taking dietary supplements that contain lycopene or omega-3 fatty acids.

NYHA functional class will be determined by patient interview at the time of recruitment to establish eligibility. Based on patients' report of symptoms associated with performing their usual activities, they are assigned a classification of I (ordinary physical activity causes no symptoms of fatigue, dyspnea, angina, or palpitations), II (symptoms with ordinary physical activity and slightly limited physical activity), III (symptoms occur with less than ordinary physical activity and produce marked limitation of activity), or IV (symptoms occur at rest and unable to carry on any physical activity without symptoms; Mills \& Haught, 1996).

Reproducibility both among different raters (inter-rater reliability) and across the same rater (intra-rater reliability) will be insured by training raters and testing them in sample patients until agreement is $100 \%$. We have extensive experience classifying patients with HF by NYHA functional class having successfully enrolled and classified a combined total of more than 1,200 patients in our previous studies.

Cognitive impairment: The Mini-Cog will be used to screen for cognitive impairment (Borson, Scanlan, Watanabe, Tu, \& Lessig, 2006). The instrument is a simple, easily administered test composed of a three-word recall and clock drawing test (scored based on a 
combination of the number of words recalled and ability to correctly draw clock screens for cognitive impairment). The instrument is a reliable, sensitive, and specific screening tool in multiple patient populations, including outpatients (Borson et al., 2006) and minorities (Borson, Scanlan, Chen, \& Ganguli, 2003; Borson, Scanlan, Watanabe, Tu, \& Lessig, 2005).

\section{C2. Intervention}

The intervention is designed to complement medical management. Therefore, both the nutrition intervention and placebo groups will continue to be medically managed by their health care provider as usual. Usual care includes advice to limit dietary sodium, but only includes brief instruction that can be provided during routine clinic visits. Other nutrition advice is not given. In order to avoid introducing the confound of extra attention paid to the intervention group, the placebo group will have the same visit and call schedule as the intervention group. Both groups will be visited at baseline, Months 3 and 6 for data collection and intervention (Table 4). There is one additional intervention visit for both groups 1-2 weeks after baseline and one intervention call 2 weeks after that visit. Both groups will receive phone calls at Months 9 and 12 for data collection (Table 4). Finally, both groups will receive phone calls to collect monthly hospitalization data and to identify problems or questions.

We will employ interventionists who are unblinded to group and data collectors who are blinded to group for the study. Interventionists are cardiovascular clinical nurse specialists working with our team for several years who assisted in the development of the intervention, who have delivered the intervention in other of our studies, and who have years of clinical and research experience. Data collectors are trained and certified individuals working with our research group who have years of data collection experience. Both interventionists and data collectors will be trained, tested and have their training updated every 6 months by the PI and co-investigators throughout the study to maintain intervention and protocol fidelity.

Dietary sodium reduction-The dietary sodium reduction component is our education and skill building intervention used successfully (see preliminary studies) and is based on the Theory of Planned Behavior (TPB; Welsh et al., 2010). The intervention addresses key factors known to promote positive health behavior changes: patient attitude, subjective norm, and perceived control (Welsh et al., 2010). The individualized theory-based teaching will be structured according to each patient's actual dietary habits using (J. A. Arcand et al., 2005; Welsh et al., 2010) three random, 24-hour diet recalls. These data will be collected by data collectors over the 2 weeks prior to baseline, Month 3, and 6 visits in both groups. A summary nutrient analysis report that provides information on the amount of vitamins and minerals in the diet in comparison to recommended levels will be generated for both groups.

The placebo group will receive information about their nutritional intake, including sodium, but will be given only generic advice about sodium intake. For example, a patient with a sodium intake of 2,500 mg/day would be advised to "keep up the good work," while one with an intake of 4,500 mg/day would be advised to "reduce salt intake." Questions will be answered generically, without using intervention specifics and strategies. The intervention group will receive the same summary nutrient analysis plus an additional report listing all 
foods consumed ranked from highest to lowest in sodium content. This will be used to identify the specific foods in diet contributing to high sodium intake and to allow the intervention to be individualized.

Given the complexity of adherence behavior (Riegel et al., 2009) (also multiple studies conducted by our team on this topic; Bentley et al., 2005; Chung et al., 2004, 2008; De Jong et al., 2011; Lee, Moser, Lennie, \& Riegel, 2010; Lee et al., 2009; Lennie, Moser, \& Habash, 2003; van der Wal, Jaarsma, Moser, van Gilst, \& van Veldhuisen, 2007, 2010; van der Wal et al., 2006; Wu, Moser, Chung, \& Lennie, 2008a, 2008b; Wu et al., 2009; Wu, Moser, Lennie et al., 2008) it is not likely that any one intervention will work for all patients. Therefore, interventions need to be flexible enough to respond to individual needs of patients as we do in our intervention. The self-management intervention is individualized for each patient's unique characteristics, starting with their eating behavior as above. Often, patients do not recognize symptoms such as weight gain, difficulty breathing, and ankle swelling as symptoms related to heart failure (Carlson, Riegel, \& Moser, 2001). Patients frequently believe they cannot control their symptoms (Carlson et al., 2001; Horowitz, Rein, \& Leventhal, 2004) or they believe dietary sodium has a minor effect on their symptoms (Schiff, Fung, Speroff, \& McNutt, 2003). Thus, we explain, at a level that the patient can understand, the pathophysiology of HF and the cause of fluid retention. Symptoms of fluid retention are listed. A clear connection is made between symptoms of fluid retention and worsening HF. The impact of high sodium foods on fluid retention is emphasized. Negative outcomes of fluid retention such as increased swelling, shortness of breath, weight gain, and rehospitalizations are then emphasized. Visual aids are provided for the entire intervention. The patient is then informed they can make a difference in their symptoms and outcomes by eating a low sodium diet. Positive outcomes of adherence to a low sodium diet are described: decreased swelling, decreased shortness of breath, decreased hospitalizations, and more energy. This information is vital in creating a positive attitude toward dietary sodium adherence. According to the TPB, this will assist the patient in forming strong beliefs that mostly positively valued outcomes will result from adhering to a low sodium diet. Signs and symptoms of fluid retention are reviewed, and patients are taught how and asked to weigh themselves daily. In order to assist the patient to develop a strong subjective norm, the value of the low sodium diet in managing HF to the patient's providers is instilled.

Perceived behavioral control is addressed by providing patients with the necessary resources to overcome impediments to following a low sodium diet. Perceived power will be increased by assisting the patient to realize he/she has multiple resources to facilitate the behavior and few barriers to impede the behavior. This includes barriers specifically identified in baseline questionnaires as well as barriers we identified: lack of knowledge, interference with socialization, and lack of food selections (Bentley et al., 2005). All teaching related to a low sodium diet will be individualized. For example, when discussing high sodium foods to avoid, specific high sodium foods found on the patient's diet recall are identified. Low sodium alternatives are discussed. Visual aides are provided for some food comparisons. For example, test tubes of sodium are compared for potato chips versus a medium potato and 3 ounces of ham versus 3 ounces of pork chop. Additional test-tubes are also used for patient demonstration. Patients are taught to read food labels, using food labels specific to foods listed on the 3-day food diary. The patient's food recall is used to plan a sample menu. 
Alternatives to high sodium foods are mutually agreed upon based on the patient's food preferences. Living arrangements and the patient's ability to cook or buy groceries are assessed with each patient. In addition, many HF patients, due to other comorbidities such as diabetes, have more than one dietary guideline to follow. This potential obstacle is also addressed for each patient. Salt substitutes are discussed and specific, written ideas for herb or spice blends are given to the patients. Written low sodium recipes are also provided to the patient.

Eating out is also an obstacle to a low sodium diet adherence. The patient's favorite restaurants are identified. A booklet, Nutrition in the Fast Lane, is given to the patient. This booklet contains sodium and other nutrient information. The patient is asked to describe what they typically order at a specific restaurant. The sodium content is looked up in the booklet and lower sodium alternatives are identified.

Lycopene supplementation-The primary source of lycopene supplementation for the intervention group will be a tomato-based juice (either low sodium tomato or V8 juice). Patients will be provided with a supply of their preferred juice at each visit and instructed to consume juice daily with breakfast or other preferred time. To provide variety, they will be given a list of other food products containing 20-25 mg of lycopene that can be substituted (Table 5). The placebo group will be provided with their choice of juices listed in Table 5 at each visit. At each visit, the interventionist will discuss any difficulties with taking supplements and problem solve if needed to enhance adherence. Based on plasma lycopene levels, adherence to the intervention was high and maintained throughout our preliminary study and control patients did not spontaneously consume higher levels of lycopene.

Omega 3 supplementation-At baseline and 3 months, patients will be provided with 3 months supplies of omega-3 fatty acid capsules (OmegaBrite; $350 \mathrm{mg}$ EPA, $50 \mathrm{mg}$ DHA/ capsule) or placebo (rice bran oil $500 \mathrm{mg} / \mathrm{capsule}$ ) depending on group assignment. They will be instructed to take three capsules per day, one with each meal. At each visit, the interventionist will problem solve if needed with patient to enhance adherence.

Baseline visit-The interventionist and data collector will visit patients in their homes. Data on socio-demographics, clinical characteristics, medications, depressive symptoms, quality of life, symptom burden, height, and weight will be collected at beginning of visit and blood will be drawn by the data collector who will leave. The interventionist will then provide all patients with a digital body weight scale, instruction on weighing daily, and ask them to do a return demonstration. Patients will also be given instructions regarding all aspects of the nutrition intervention/placebo.

\section{Visit 2}

Nutrition intervention group: The interventionist will make a second home visit approximately 1-2 weeks after baseline to both groups. The interventionist will review information previously presented and in both groups will determine any problems to following any of the three components of the intervention. 


\section{Follow-up phone call}

Placebo group: Follow-up phone call will occur within 2 weeks of Visit 2. The interventionist will inquire about general welfare, ask whether the patient is having difficulties with the taking capsules or juice, and answer any questions.

Nutrition intervention group: Follow-up phone call for the intervention group will occur within 2 weeks of Visit 2 . The interventionist will reinforce previously taught information, review success in meeting goals, help patients problem solve any new barriers, and applaud positive changes made in the diet, and discuss problems or concerns related to capsules or juice intake.

Month 3 and month 6 visits-The interventionist and data collector will visit patients in their homes. The data collector will obtain all appropriate data and then leave.

Placebo group: The research nurse will review the summary nutrient analysis report generated from the three 24-hour food recalls collected in the 2 weeks prior to the visit and answer all questions.

Nutrition intervention group-Prior teaching will be reviewed and reinforced. The research nurse will review the summary nutrient analysis report and the list of foods ranked by sodium content generated from the three 24-hour food recalls collected in the 2 weeks prior to visit. The nurse and patient will jointly identify low sodium alternatives for foods high in sodium. Goals and strategies for substituting high sodium foods with low sodium alternatives will be jointly developed. The interventionist will help the patient problem solve ways to overcome any new barriers identified and discuss any problems or concerns related to capsules or juice intake.

\section{C3. Procedure}

Permission for this study will be obtained from the University of Kentucky Institutional Review Board. Patients will be referred to this project by physicians or nurse practitioners in the Chandler Medical Center clinics who will obtain permission from patients for nurse recruiter to contact. Trained nurse research assistants will confirm eligibility and screen for cognitive impairment. Those identified as impaired will be informed they do not meet study eligibility. For eligible patients, study requirements will be explained and if patient agrees to participate, signed informed consent will be obtained. The patient will then be randomly assigned to either the nutrition intervention or placebo group using a randomization table stratified by gender. The baseline visit by the interventionist and data collector will be scheduled. Over the 2 weeks prior to the baseline, 3-, and 6-month visits a data collector will call on 3 days ( 2 random weekdays and 1 random weekend day) to obtain 24-hour diet recalls and generate nutrient analysis reports. The interventionist will make baseline, followup phone call, 3-, and 6-month visits as described in the intervention.

Blood will be drawn at the baseline, Months 3 and 6 visits. Blood will be placed on ice and transported to the Biochemical Analysis Laboratory of the UK CR-DOC to be spun down and plasma or serum, depending on analyte, allocated into tubes and stored at -70 until 
analyzed. Red blood cells for fatty acid analysis will also be frozen and stored. Samples to be sent to our collaborator's laboratory will be shipped overnight by the UK CR-DOC on dry ice according to International Air Transportation Association Training Packing Instruction 650 for Diagnostic Specimens. In Years 2 and 3, when volume of visits is high, we will have two data collectors for blood draws at the 6-month time point.

Data on socio-demographic, clinical characteristics, medications, depressive symptoms, quality of life, and symptom burden will be collected in person at baseline. Data on medication changes, quality of life, and symptom burden will be collected in person at 3and 6-month visits. Hospitalization and mortality data will be collected monthly for 12 months to obtain patient outcomes. The data collectors will review medical records and call patients or family members monthly to obtain information about hospitalization and mortality. Data on quality of life and symptom burden at 9 and 12 months will be collected by telephone during the corresponding monthly phone call to collect hospitalization data. Patients will be compensated $\$ 25$ for their time at the baseline, Months 3 and 6 visits, and at the final 12-month phone call.

\section{C4. Measurement of Variables}

Rationale for timing of variable measurement-Baseline measurement provides indicators of the success of randomization and control values for between-group comparisons at other time points. Measurement at the 3-month time point provides indicators of intermediate effects of the intervention while the 6-month time point provides indicators of long-term adherence and insights into the biological mechanisms underlying hypothesized changes in symptoms and quality of life. The primary interest in measurement at the 9- and 12-month time points is to determine long-term effects on the primary study outcomes of symptom burden, quality of life, and hospitalization or death. While it would be of interest to also measure biological markers at the 9- and 12-month time points this would require two visits for blood draws increasing subject burden. Given that the mechanistic components of the intervention will be demonstrated by measurement of biological markers at the baseline, 3 , and 6 months, we do not believe the added subject burden or cost merits the limited additional information that would be gained by requiring visits for blood draws at 9 and 12 months.

Specific Aim 1-To determine the effects of a 6-month nutrition intervention on symptom severity, health-related qualtiy of life, and HF rehospitalization or all-cause death at 3-, 6-, 9- and 12-month time points.

Symptom burden: Physical symptom burden will measured using items from the Memorial Symptom Assessment Scale-Heart Failure (MSAS-HF) (Zambroski et al., 2005). The MSAS-HF is a 32-item questionnaire adapted from Portenoy's Memorial Symptom Assessment Scale that is designed to provide multidimensional information about symptoms experienced by patients with HF. Patients will be first asked if the symptom was present during the previous 7 days. If present, three characteristics of each symptom will be rated: frequency of symptom, severity of symptom, and degree symptom of distress. Frequency is rated on a scale from 1 to 4 (rarely to almost constantly), severity rated on a scale from 1 to 
4 (mild to very severe) and distress rated on a scale from 0 to 4 (not at all to very severe).

Burden score for each symptom can range from 0 (no burden) to 12 (greatest symptom frequency, severity, and distress). For the purposes of testing Hypothesis 1a, incidence and burden score for three symptoms (shortness of air, edema, and lack of energy) will be compared between groups. The combined total symptom burden score (shortness of air + edema + lack of energy) will also be compared. The full instrument has three subscales that measure psychological, physical, and HF-specific symptoms. Subscales have reported reliability estimates of $0.92,0.83,0.87$, and 0.73 , respectively, in a similar patient population (Zambroski et al., 2005).Total symptom subscale scores will be used in future secondary analyses to explore the effect of the intervention on total symptom burden.

Quality of life: Quality of life will be measured using a disease-specific instrument, the Minnesota Living with Heart Failure Questionnaire (LHFQ; Rector \& Cohn, 1992a; Rector, Johnson, et al., 1993; Rector, Kubo, \& Cohn, 1987, 1993; Rector et al., 1995). The instrument measures patients' perception of how much their HF and its treatment affects their ability to live as they want, and since its development it has been widely used in research and clinical practice. It consists of 21 questions rated on a scale from 0 (no effect) to 5 (very much). Item ratings are summed for a total score that can range from 0 to 105 . Higher scores reflect worse QOL. Questions concern a variety of physical and psychological aspects of living with HF and include activities of daily living, economic issues, ability to work, enjoyment of leisure time activities, relations with family and friends, sexual activity, side effects from medications, depression, and impact of HF symptoms. The LHFQ is the most commonly used disease-specific instrument used in HF research and is an appealing instrument because it is inexpensive, short, easily understood by ill and elderly individuals, self-administered, and easy to score.

Several investigators have examined the psychometric properties of the LHFQ in patients with HF and found strong internal consistency reliabilities of the total, physical, and emotional scales (Cronbach's alphas ranging from .88 to .93; Bennett et al., 2002; Heo, Moser, Riegel, Hall, \& Christman, 2005; Rector \& Cohn, 1992b; Rector et al., 1987; Riegel et al., 2002). Support for the construct validity of the LHFQ has been reported in several studies (Gorkin et al., 1993; Middel et al., 2001; Quittan et al., 2001). The LHFQ discriminates among NYHA functional class groups (Bennett et al., 2002). The LHFQ was more responsive to clinically important changes than the MOS SF-12 (Bennett et al., 2003). The LHFQ was used in our study that demonstrated a relationship between HRQOL and rehospitalization or mortality (Moser et al., 2009).

Hospitalization and mortality outcomes: HF rehospitalization and all-cause mortality will be considered to have relative equivalence for two reasons. First, hospitalization is not a routine component of care under current HF management guidelines (Hunt et al., 2009). Patients are typically not hospitalized unless they develop an exacerbation that would be life-threatening if not admitted for treatment. Second, the combined endpoint of HF rehospitalization and all-cause mortality is useful, even preferred, when study variables affect multiple end-points (DeMets \& Califf, 2002). HF rehospitalization will be determined by use of a combination of three methods we use previously in order to capture all 
hospitalizations and confirm correct classification of hospitalization (Lennie et al., 2011; Moser et al., 2010; Wu et al., 2008a).

Hospital administrative records: UK Medical Center uses an integrated data delivery system to track all patient encounters and document each patient contact with the healthcare system within the medical center. Thus, comprehensive data are available on dates, times and reasons for all hospitalizations.

Medical record review: We will corroborate the data from administrative records by performing medical record review of each encounter noted in the system or reported to be outside the system. An advanced practice nurse with clinical expertise in the management of patients with HF blinded to group assignment will review hospitalizations to ensure accurate categorization of reason. The nurse will be specifically trained to collect these data. The diagnosis of HF exacerbation will be confirmed according to established criteria (Hershberger et al., 2001; Krumholz et al., 2002).

Patient/family interview: There is always the possibility that a patient will be admitted to a different hospital. Therefore, patients/families will be interviewed monthly to obtain selfreports of admissions that can be used to trigger search for supporting administrative data and medical record review data. Research associates will be trained to carefully interview patients to identify all admissions. Patients will be asked to keep a diary of all hospital admissions to reinforce their memory for these events (Hershberger et al., 2001). For hospital admissions outside the system, discharge reports released to the patient will be reviewed.

All-cause mortality will be determined by a combination of medical record review, discussion with patients' health care providers and family, automated hospital records and review of county death records to obtain date and cause of death. At enrollment, patients will be asked for contact information for a close friend or next of kin to be used if they are unable to be contacted. If neither the patient nor these contacts can be located during followup or if additional information is needed, the county death records will be searched. We used these methods successfully to accurately categorize deaths (Lennie et al., 2011; Moser, Stevenson, Woo, \& Stevenson, 1994; Wu et al., 2009).

Specific Aim 2-To compare dietary sodium intake, markers of oxidative stress, and proinflammatory/anti-inflammatory cytokine levels of patients in the nutrition intervention group with patients in the placebo group at 3-and 6-month time points.

Dietary sodium intake: Twenty-four hour diet recall interviews will be used estimate sodium intake and to identify high sodium foods and eating patterns for the sodium reduction component of the intervention. Patients will be called on two randomly selected weekdays and 1 weekend day during 2 weeks prior to baseline visit, Weeks 10 and 11 of intervention (prior to Month 3 time point visit), and Weeks 34 and 35 of intervention (prior to Month 6 time point visit). The interviews will be conducted by trained research assistants under the supervision of Dr. Thomas. The diets will be analyzed using Nutrition Data Systems-R (NDS-R) software (NCC, University of Minnesota) which is designed to obtain 
reliable food intake data via interviews. The NDS-R is a sophisticated diet analysis program that is among the most complete and accurate diet analysis systems available. The software has the capacity to provide output for over 102 nutrients and nutrient ratios. The database contains nutrient content for more than 19,000 foods including over 160,000 variants in food preparation method and ingredients. The database also contains nutrient information for diet supplements and over 7,800 brand name and ethnic foods. The database contains dietary supplements and medications containing sodium. Finally, the software allows direct input of recipes for homemade foods.

Oxidative stress markers: These markers will be measured in the laboratories of Dr. Brucker. Because it is difficult to measure reactive oxygen species directly in humans, indirect markers of oxidative stress will used. Elevated levels of malondialdehyde and 8-isoPGF2a isoprostane will serve as markers of increased lipid peroxidation due to oxygen-free radical production exceeding antioxidant capacity. Levels of these biomarkers are expected to decrease in response to the lycopene component of the intervention (Polidori et al., 2002, 2004). Elevated levels of uric acid indicate increased production of oxygen-free radicals due to increased xanthane oxidase activity. Because oxygen-free radicals are produced downstream as a consequence of uric acid formation, uric acid levels will be used to indicate presence of oxidative stress (Doehner \& Anker, 2005). We expect patients with high uric acid levels receiving the intervention to have lower levels of malondialdehyde and 8-isoPGF2a isoprostane than patients with high uric acid levels receiving the placebo. Venous blood will be drawn into vacutainers containing trisodium citrate, EDTA and/or BHT depending on the analysis, centrifuged in a refrigerated centrifuge and plasma separated and allotted to micro-tubes and kept at $-70^{\circ} \mathrm{C}$ prior to analysis.

Malondialdehyde: Lipid peroxidation, mainly malondialdehyde, will be measured fluorometrically as thiobarbituric acid-reactive substances (TBARS) according to the modified method using a Gilford Fluoro IV spectrofluorometer (Gilford Instrument, Oberlin, $\mathrm{OH})$ with excitation at $515 \mathrm{~nm}$ and emission at $550 \mathrm{~nm}$ after isobutyl alcohol extraction. 1,1,3,3-Tetraethoxypropane will be used as the standard (Ibrahim et al., 1997).

8-iso-PGF2a isoprostane will be measured in plasma using Enzo Life Sciences direct ELISA kits. Sample concentrations will be determined by measuring optical density in a microplate reader and calculated from a standard curve using a 4-parameter curve fit.

Uric acid will be measured using the colorimetric method at $590 \mathrm{~nm}$ as described in the QuantiChrom Uric Acid Assay Kit by BioAssay Systems. For all assays, samples and standards will be run in duplicate and inter- and intra-assay CV determined to assure accuracy and reproducibility.

Pro- and anti-inflammatory cytokines: Serum levels of TNFa, soluble TNF receptors: sTNFR1 and sTNFR2 will be measured as markers of proinflammatory cytokine activity (Kell et al., 2002; Rauchhaus et al., 2000). Because the effects of proinflammatory cytokine activity are moderated by anti-inflammatory cytokines, interleukin-10 (IL-10) will be measured as a marker of anti-inflammatory cytokine activity. IL-10 has potent antiinflammatory properties including down regulation of TNFa, IL-1, and IL-6 production 
(Asadullah, Sterry, \& Volk, 2003). IL-10 is higher in patients with HF than similarly aged controls (Yamaoka, Yamaguchi, Okuyama, \& Tomoike, 1999). Unfortunately, these higher levels of IL-10 likely did not convey protection from inflammation as the ratio of IL-10 to TNFa was lower in patients with HF. This suggests that despite having higher IL-10 levels, proinflammatory cytokine activity was actually greater in patients with HF. Consistent results have been reported in which the lowest ratio of IL-10 to TNFa was found in the most symptomatic patients (Aukrust et al., 1999; Stumpf, Lehner, Yilmaz, Daniel, \& Garlichs, 2003). Low IL-10 levels also may be related to cardiovascular events. These data indicate that examination of the relationship between proinflammatory and anti-inflammatory cytokines is necessary to obtain a full understanding of the role of inflammation in HF symptoms. Cytokines and receptors will be measured using commercially available ELISA kits (BioSource) by the Biochemical Analysis Laboratory of the University of Kentucky Center for Clinical and Translational Science. Sample concentrations will be determined by measuring optical density in a microplate reader and calculated from a standard curve using a 4-parameter curve fit. Samples and standards will be run in duplicate and inter- and intraassay CV determined to assure accuracy and reproducibility. Samples in which the CV exceeds $10 \%$ will be rerun.

Specific Aim 3-To compare three markers of intervention adherence, body weight, plasma lycopene, and erythrocyte omega-3 index at 3-and 6-month time points between intervention and placebo group.

Body weight: Patients will be provided with a high capacity (400 lbs) digital bathroom scale with a large display screen for easy reading (Eatsmart Precision Plus, Wyckoff, NJ). They will be instructed to weigh themselves at the same time each morning in light clothing after voiding. The research nurse will verify the ability of patients to accurately obtain body weight by having patients do a return demonstration during a home visit. Body weights will be obtained on each day of the 24-hour diet recall and home visits.

Plasma lycopene levels: Plasma lycopene will be measured in the laboratory of Dr. Schwartz at The Ohio State University. Venous blood drawn into EDTA vacutainer tubes (Fisher Scientific, Pittsburg, PA) will be centrifuging at $1,000 \mathrm{~g}$ at $4^{\circ} \mathrm{C}$ for 10 minutes and plasma extracted.

Lycopene extraction: Plasma $(0.5 \mathrm{ml})$ is mixed with $0.5 \mathrm{ml}$ ethanol containing $0.1 \%$ butylated hydroxytoluene and $2 \mathrm{ml}$ of HEAT ( 10 hexane/ 6 ethanol/ 7 acetone/7 toluene). The mixture is vortexed and centrifuged for 5 minutes at $300 g$. The upper non-polar layer is removed and the remaining aqueous plasma mixture extracted twice more. The three nonpolar extracts are combined and dried under nitrogen. The dried extract is stored at $-80^{\circ} \mathrm{C}$ until HPLC-PDA analysis.

Lycopene HPLC-PDA (photodiode array) analysis: Samples will be reconstituted in 1:1 $200 \mu \mathrm{lmethanol/Methyl} \mathrm{tert-butyl} \mathrm{ether} \mathrm{(MTBE)} \mathrm{and} \mathrm{filtered} \mathrm{through} \mathrm{a} \mathrm{nylon} \mathrm{syringe} \mathrm{filter.}$ Samples will be placed into the HPLC system (Waters 996) interfaced with a PDA detector (Waters 2996). Separation will be achieved using a YMC C-30 column (Waters Corp., Milford, MA). A 30-minute gradient method employing methanol and MTBE will be used 
with a flow rate of $1.3 \mathrm{ml} /$ minute, column temperature $=30^{\circ} \mathrm{C}$, and injection volume $=20 \mu \mathrm{l}$. Lycopene will be quantified using an external calibration curve.

Omega-3 index: Omega-3 index will be defined as the ratio of EPA plus DHA as a percentage of total fatty acids in the cell membrane of erythrocytes (Harris, 2008). Erythrocyte membrane fatty acid analysis will be conducted in the laboratories of Dr. Bruckner. Venous blood will be drawn into vacutainers containing EDTA and BHT, centrifuged in a refrigerated centrifuge and the packed RBC separated allotted to microtubes and kept at $-70^{\circ} \mathrm{C}$ prior to analysis. All RBC samples will be spiked with 15:0 as an internal standard. Samples will then be homogenized, and lipids extracted using hexane:isopropanol (3:2 [v:v]) containing $0.05 \%$ butylated hydroxy-toluene. Total lipids will be transmethylated using $14 \%$ boron trifluoride-methanol. Methylated samples, after concentrating under nitrogen gas flow, will be injected into a gas chromatograph equipped with a flame ionization detector and an Omegawax ${ }^{\mathrm{TM}}$ Capillary GC Column (length, $30 \mathrm{~m}$; inside diameter, $0.3-0 \times 0.25 \mathrm{~mm}$ ). Nitrogen flow will be maintained at between 1 and 10 $\mathrm{ml} / \mathrm{minute}$ by use of an electronic pressure control. Temperature program for the column will be with an initial temperature of $140^{\circ} \mathrm{C}$ increased at a rate of $20^{\circ} \mathrm{C} /$ minute up to $280^{\circ} \mathrm{C}$ and held for 5 minutes. Peaks will be identified using fatty acid standards run with each batch of samples (Szabo, Ibrahim, Sunvold, \& Bruckner, 2003).

Measurement of other variables of interest: To completely characterize patients and obtain data on potential intervening variables, information concerning the following variables will be collected: age, sex, race/ethnicity, marital status and whether the patient lives alone, education level, time since diagnosis, medication regimen, co-morbidity, and body mass index. Data on age, sex, race/ethnicity, marital status, whether patient lives alone, and education level will be collected by patient interview. Prescribed medication regimen (i.e., drugs, doses, frequencies) will be obtained from patient interview and medical record review to confirm patient report. Time since diagnosis will be determined by patient interview and medical record review to document diagnosis of HF. The conversion of asymptomatic ventricular dysfunction to overt HF usually is heralded by the occurrence of activity intolerance as a result of one or both of the most common, dyspnea or fatigue. Thus, length of time since diagnosis is the most commonly used indicator of duration of HF.

Co-morbidity will be measured at enrollment using the Charlson Index, interview format (Katz, Chang, Sangha, Fossel, \& Bates, 1996). Scores can range from 0 to 34 but because each subject has HF they will have a score $\geq 1$. Responses are summed, weighted, and indexed into one of three categories (low, moderate, or high) according to the published method. Reliability and validity have been demonstrated; specifically with regard to validity, predictive validity was demonstrated when comorbidity category predicted mortality, complications, health care resource use, length of hospital stay, discharge disposition, and cost (Charlson, Pompei, Ales, \& MacKenzie, 1987; Katz et al., 1996).

Body mass index (BMI) is recognized to be related to both HF symptoms and paradoxically to longer event-free survival (Curtis et al., 2005; Horwich et al., 2001; Hunt et al., 2009). BMI will be defined as body weight measured to the nearest $100 \mathrm{~g}$ divided by height measured to the nearest meter square. Measurements by experienced research staff will be 
taken on patients without shoes and in light clothing using a digital scale and a portable, professional grade stadiometer (Heyward \& Wangner, 2004).

Emotional distress is common in patients with HF and associated with symptom burden (Jurgens et al., 2009). Depressive symptoms will be measured using the Beck Depression Inventory II (BDI-II). The BDI-II is an updated and revised version of the Beck Depression Inventory that consists of 21 items (Arnau, Meagher, Norris, \& Bramson, 2001; Steer, Ball, Ranieri, \& Beck, 1999; Steer, Clark, Beck, \& Ranieri, 1999). Each item is rated on a 4-point scale ranging from 0 to 3 . Item ratings are summed and total scores can range from 0 to 63 ; higher scores indicate a greater level of depressive symptoms. A person with a total score of 14-19 is considered to have mild depressive symptoms; total scores of 20-28 indicate moderate depressive symptoms, total scores from 29 to 63 reflect severe depressive symptoms (Beck, Brown, \& Steer, 1996). Use of the BDI-II in previous cardiac studies has demonstrated that the instrument is a sensitive depressive symptom screening tool (Ariyo et al., 2000; Beck, Epstein, Brown, \& Steer, 1988; Bush et al., 2001; Jiang et al., 2001; Lane, Carroll, Ring, Beevers, \& Lip, 2001). Previous investigators have demonstrated the reliability and validity of the BDI in patients with CAD and HF (Ahern et al., 1990; Beck et al., 1988; Bush et al., 2001; Carney et al., 2000, 2001; Frasure-Smith, Lesperance, \& Talajic, 1995; Jiang et al., 2001; Lane et al., 2001; Lesperance, Frasure-Smith, Talajic, \& Bourassa, 2002; Stein et al., 2000).

\section{C5. Data Analysis and Power Considerations}

Analyses-Data analysis will begin with a descriptive examination of the variables including frequency distributions, means and standard deviations, medians, and interquartile ranges, as appropriate to the level of measurement. Baseline comparisons of demographic/ personal and outcome variables between those who dropped out and those who completed all waves of data collection will be determined using two-sample $t$-tests or chi-square tests, and the rate of retention will be compared between the two treatment arms using the chisquare test of association to test for differential drop-out. To control the overall Type I error rate, the significance level for inferential statistical tests will be Bonferroni-corrected. It is anticipated that the alpha level used to investigate the three study aims will typically be .01 . The focus of each of the aims is to test for group differences between the intervention and placebo groups over time, with all four time points included in the Specific Aim 1 and the 3and 6-month time points included in the Specific Aims 2 and 3. For continuous outcomes, these comparisons over time will be accomplished using repeated measures analysis of variance with Fisher's least significant difference procedure used for post hoc comparisons. For time to hospitalization, survival analysis with the logrank test will be used to determine an overall group difference, while Cox regression will compare the groups, adjusting for demographic and relevant clinic covariates.

Power-For the repeated measures ANOVA models, with an alpha level of .01, a medium effect size, 75 in each group, and a modest correlation among observations over time from the same individual, the ANOVA $F$ tests will have at least $85 \%$ power to detect differences between groups, differences over time, or a group by time interaction. A medium effect size in this context is defined as a difference such that the ratio of the standard deviation of the 
means to the standard deviation of the observations within the populations is as small as 0.25 (Cohen, 1988). Results provided in Section A3.1 suggest that effect sizes for differences in QOL between those with and without at least one of the three major symptoms are large, so the assumption of at least a medium effect size is likely to be conservative. With 75 subjects per group and an alpha level of .01, the power of the logrank test to detect a group difference in time to rehospitalization will be approximately $80 \%$ if the hazard ratio for the comparison is as small as 2 . One way to obtain a hazard ratio of this magnitude would be if the rehospitalization percentages are $20 \%$ and $45 \%$ in the intervention and placebo groups, respectively. While it is not possible to estimate the power of Cox regression, it has been established that Cox regression is at least as powerful as the corresponding logrank test (Schoenfeld, 1983). Power estimates were obtained using nQuery Advisor (Elashof, 2005).

Figure 2 presents the timeline for the study.

\section{C6. Potential Problems}

Dietary sources of additional carotenoids and other antioxidants such as vitamins E and A (Polidori et al., 2002), as well as omega-3 fatty acids could alter or mask the effects of the intervention. Given that the intent of this study is to test an intervention that can be implemented in community dwelling patients receiving palliative care, participants will be instructed to consume their normal diet plus supplements. Consequently total carotenoid and omega-3 intake from 3-day 24-hour recalls and supplements will be used in the analyses. The 24-hour recalls will also be used to estimate intake of additional antioxidants which will be controlled for in the analyses. Poor adherence is also a potential problem. We will have measures of serum lycopene and erythrocyte fatty acid composition that will allow us analyze data with respect to actual levels of these nutrients in the body rather than rely only on self-report of adherence.

\section{C7. Potentially Hazardous Procedures/Situations/Materials}

The primary risk of hazardous exposure is to blood from venipuncture. Universal precautions will be used to minimize possible exposure to blood.

\section{Summary Statement Excerpts SRG Action: Impact/Priority Score: 27}

\section{Resume and Summary of Discussion}

This application from University of Kentucky, submitted in response to RFA-NR-11-006 focuses on an important aspect of advanced heart failure therapy using nutritional and behavioral approach. This intervention is likely to translate into self care of the patients and improve the overall well being and outcomes. Precisely, the investigative team embarks on improving advanced heart failure (HF) symptoms and quality of life in patients through a low cost, easily administered intervention of dietary sodium restriction coupled with lycopene and omega-3 fatty acid supplementation. The study topic is important and timely since the outcome of the proposed aims if successful, are likely to significantly advance the scientific knowledge and clinical intervention of advanced heart failure. The review group has expressed following merits that include theory-based intervention guided and informed 
by prior work; strong team and excellent environment; expertise in RCT; feasible and easily administered protocol; low cost, easily administered home-based, nutrition intervention is considered innovative; approach is well articulated. However on the other hand, the review group stated following weaknesses the include (1) respondent burden is a concern; (2) too wide an age range (18-90); (3) unclear how optimization of medical therapy and evaluation of heart failure are operationalized; (4) unclear if the omega 3 levels influence QOL; (5) generalizability from one site; (6) better link needed between eating and suffering in advanced HF as eating is a coping strategy; (7) focuses only on physiology- no psychosocial outcomes. Overall the panel has expressed high level of enthusiasm (with correctable minor weaknesses) based on high feasibility and home-based nutritional intervention that can be easily administered and affordable and is highly likely to move the field of advanced heart failure therapy forward.

\title{
Critique 1
}

\author{
Significance: 2 \\ Investigator(s): 1 \\ Innovation: 2
}

Approach: 2

Environment: 1

Overall impact-This application is highly responsive to the FOA and, as such, addresses an important and timely topic of national significance. The proposed study is guided and informed by prior conceptual and methodological work conducted by the multidisciplinary team of investigators. The assembled team has research and clinical experience and expertise with symptom management, nutritional interventions and those designed to improve overall quality of life in advanced HF. The research environment(s) are particularly well-suited to fulfillment of the major study aims. Collective past contributions to this area of inquiry including those relevant to the integrated, theory-based proposed intervention add to the likelihood of realizing study aims. If hypotheses are supported, the results of this study have potential to improve symptoms and quality of life in individuals with advanced $\mathrm{HF}$ in a low-cost and feasible (easily-administered) manner. Given the data to be collected, the longitudinal nature/design of the RCT, and the patient population, some concern for respondent burden exists.

\section{Critique 2}

\author{
Significance: 3 \\ Investigator(s): 2 \\ Innovation: 3
}

Approach: 3

Environment: 2 
Overall impact-This project address an important aspect of heart failure therapy: nutrition using a well defined behavioral approach and instrumented by an experienced and solid team of investigators. The intervention is simple, and if the behavioral aspect of self management is learned by the patients, the benefit of this intervention (goal setting, empowerment) may translate to other aspects of the self care of the patients and improve the overall well being and outcomes. The enthusiasm of this reviewer is ameliorated by the following aspects: the preliminary data only modestly support the expected changes in clinical outcomes, the focus on just the nutrition may lack the comprehensive nature of palliative care (so needed in this population), the strength of the approach to achieve such a complex behavior (eating in the context of a suffering patient), accrual from just one center.

\title{
Critique 3
}

\author{
Significance: 3 \\ Investigator(s): 1 \\ Innovation: 3
}

Approach: 3

Environment: 1

Overall impact-[reiteration of aims deleted] Strengths include a double blind placebo controlled study design, ample experience with similar studies, and a low cost intervention.

Significant weaknesses include an application devoid of a palliative care framework, lack of palliative care expertise, lack of clinical correlation of the numerous physiologic markers in the context of end of life, and an application replete with grammatical errors and inconsistencies.

\section{Acknowledgments}

This application was supported in part by National Institutes of Health grants: R01NR009280, R01NR008567, and 1P20NR010679 from National Institute of Nursing Research; and UL1RR033173 [TL1 RR033172, KL2

RR033171] from the National Center for Research Resources. The content is solely the responsibility of the authors and does not necessarily represent the official views of the National Institutes of Health.

\section{References}

Ahern DK, Gorkin L, Anderson JL, Tierney C, Hallstrom A, Ewart C. The CAPS Investigators. Biobehavioral variables and mortality or cardiac arrest in the Cardiac Arrhythmia Pilot Study (CAPS). American Journal of Cardiology. 1990; 66:59-62. [PubMed: 2193497]

Alla F, Briancon S, Guillemin F, Juilliere Y, Mertes PM, Villemot JP, Zannad F. Self-rating of quality of life provides additional prognostic information in heart failure. Insights into the EPICAL study. European Journal of Heart Failure. 2002; 4:337-343. [PubMed: 12034160]

Anker SD, Doehner W, Rauchhaus M, Sharma R, Francis D, Knosalla C, Coats AJ. Uric acid and survival in chronic heart failure: Validation and application in metabolic, functional, and hemodynamic staging. Circulation. 2003; 107:1991-1997. [PubMed: 12707250]

Arcand J, Ivanov J, Sasson A, Floras V, Al-Hesayen A, Azevedo ER, Newton GE. A high-sodium diet is associated with acute decompensated heart failure in ambulatory heart failure patients: A prospective follow-up study. American Journal of Clinical Nutrition. 2011; 93:332-337. ajcn. 110.000174 [pii]. 10.3945/ajcn.110.000174 [PubMed: 21084647] 
Arcand JA, Brazel S, Joliffe C, Choleva M, Berkoff F, Allard JP, Newton GE. Education by a dietitian in patients with heart failure results in improved adherence with a sodium-restricted diet: A randomized trial. American Heart Journal. 2005; 150:716. [PubMed: 16209971]

Ariyo AA, Haan M, Tangen CM, Rutledge JC, Cushman M, Dobs A, Furberg CD. Depressive symptoms and risks of coronary heart disease and mortality in elderly Americans. Cardiovascular Health Study Collaborative Research Group. Circulation. 2000; 102:1773-1779. [PubMed: 11023931]

Arnau RC, Meagher MW, Norris MP, Bramson R. Psychometric evaluation of the Beck Depression Inventory-II with primary care medical patients. Health Psychology. 2001; 20:112-119. [PubMed: 11315728]

Asadullah K, Sterry W, Volk HD. Interleukin-10 therapy-Review of a new approach. Pharmacology Review. 2003; 55:241-269.

Aukrust P, Ueland T, Lien E, Bendtzen K, Muller F, Andreassen AK, Gullestad L. Cytokine network in congestive heart failure secondary to ischemic or idiopathic dilated cardiomyopathy. American Journal of Cardiology. 1999; 83:376-382. [PubMed: 10072227]

Basu A, Imrhan V. Tomatoes versus lycopene in oxidative stress and carcinogenesis: Conclusions from clinical trials. European Journal of Clinical Nutrition. 2007; 61:295-303. 1602510 [pii]. 10.1038/sj.ejcn.1602510 [PubMed: 16929242]

Beck, AT.; Brown, G.; Steer, RA. Beck Depression Inventory II Manual. San Antonio, TX: The Psychological Corporation; 1996.

Beck AT, Epstein N, Brown G, Steer RA. An inventory for measuring clinical anxiety: Psychometric properties. Journal of Consulting and Clinical Psychology. 1988; 56:893-897. [PubMed: 3204199]

Bennett SJ, Huster GA, Baker SL, Milgrom LB, Kirchgassner A, Birt J, Pressler ML. Characterization of the precipitants of hospitalization for heart failure decompensation. American Journal of Critical Care. 1998; 7:168-174. [PubMed: 9579241]

Bennett SJ, Oldridge NB, Eckert GJ, Embree JL, Browning S, Hou N, Murray MD. Comparison of quality of life measures in heart failure. Nursing Research. 2003; 52:207-216. [PubMed: 12867777]

Bennett SJ, Oldridge NB, Eckert GJ, Embree JL, Browning S, Hou N, Murray MD. Discriminant properties of commonly used quality of life measures in heart failure. Quality of Life Research. 2002; 11:349-359. [PubMed: 12086120]

Bentley B, De Jong MJ, Moser DK, Peden AR. Factors related to nonadherence to low sodium diet recommendations in heart failure patients. European Journal of Cardiovascular Nursing. 2005; 4:331-336. [PubMed: 15935733]

Biddle, MJ.; Lennie, TA.; Bricker, GV.; Kopec, RE.; Schwartz, SJ.; Moser, DK. Lycopene dietary intervention: A pilot study in patients with heart failure. in review

Biddle MJ, Payne-Emerson H, Heo S, Song E, Lennie TA, Dunbar SB, Moser DK. Lycopene intake predicts event-free survival in patients with heart failure. Circulation Research. 2008; 118:S290.

Borson S, Scanlan JM, Chen P, Ganguli M. The Mini-Cog as a screen for dementia: Validation in a population-based sample. Journal of the American Geriatrics Society. 2003; 51:1451-1454. 51465 [pii]. [PubMed: 14511167]

Borson S, Scanlan JM, Watanabe J, Tu SP, Lessig M. Simplifying detection of cognitive impairment: Comparison of the Mini-Cog and Mini-Mental State Examination in a multiethnic sample. Journal of the American Geriatrics Society. 2005; 53:871-874. JGS53269 [pii]. 10.1111/j. 1532-5415.2005.53269.x [PubMed: 15877567]

Borson S, Scanlan JM, Watanabe J, Tu SP, Lessig M. Improving identification of cognitive impairment in primary care. International Journal of Geriatric Psychiatry. 2006; 21:349_ 355.10.1002/gps.1470 [PubMed: 16534774]

Bush DE, Ziegelstein RC, Tayback M, Richter D, Stevens S, Zahalsky H, Fauerbach JA. Even minimal symptoms of depression increase mortality risk after acute myocardial infarction. American Journal of Cardiology. 2001; 88:337-341. [PubMed: 11545750]

Carlson B, Riegel B, Moser DK. Self-care abilities of patients with heart failure. Heart \& Lung. 2001; 30:351-359. [PubMed: 11604977] 
Carney RM, Blumenthal JA, Stein PK, Watkins L, Catellier D, Berkman LF, Freedland KE. Depression, heart rate variability, and acute myocardial infarction. Circulation. 2001; 104:2024 2028. [PubMed: 11673340]

Carney RM, Freedland KE, Stein PK, Skala JA, Hoffman P, Jaffe AS. Change in heart rate and heart rate variability during treatment for depression in patients with coronary heart disease. Psychosomatic Medicine. 2000; 62:639-647. [PubMed: 11020093]

Ceconi C, Curello S, Bachetti T, Corti A, Ferrari R. Tumor necrosis factor in congestive heart failure: A mechanism of disease for the new millennium? Progress in Cardiovascular Disease. 1998; 41(1 Suppl 1):25-30. [PubMed: 9715820]

Charlson ME, Pompei P, Ales KL, MacKenzie CR. A new method of classifying prognostic comorbidity in longitudinal studies: Development and validation. Journal of Chronic Disease. 1987; 40:373-383.

Chin MH, Goldman L. Correlates of early hospital readmission or death in patients with congestive heart failure. American Journal of Cardiology. 1997; 79:1640-1644. [PubMed: 9202355]

Chung ML, Lennie TA, de Jong M, Wu JR, Riegel B, Moser DK. Patients differ in their ability to selfmonitor adherence to a low-sodium diet versus medication. Journal of Cardiac Failure. 2008; 14:114-120. S1071-9164(07)01087-1[pii]. 10.1016/j.cardfail.2007.10.010 [PubMed: 18325457]

Chung ML, Lennie TA, Worral-Carter L, Bentley B, Moser DK. Gender differences in adherence to the sodium-restricted diet in patients with heart failure. Circulation. 2004; 110(Supplement):III-739.

Clinton SK. Lycopene: Chemistry, biology, and implications for human health and disease. Nutrition Review. 1998; 56(2 Pt 1):35-51.

Cohen S. Psychosocial models of the role of social support in the etiology of physical disease. Health Psychology. 1988; 7:269-297. [PubMed: 3289916]

Conraads VM, Bosmans JM, Vrints CJ. Chronic heart failure: An example of a systemic chronic inflammatory disease resulting in cachexia. International Journal of Cardiology. 2002; 85:33-49. [PubMed: 12163208]

Curtis JP, Selter JG, Wang Y, Rathore SS, Jovin IS, Jadbabaie F, Krumholz HM. The obesity paradox: Body mass index and outcomes in patients with heart failure. Archives of Internal Medicine. 2005; 165:55-61. [PubMed: 15642875]

Dantzer R. Cytokine, sickness behavior, and depression. Immunology and Allergy Clinics of North America. 2009; 29:247-264. S0889-8561(09)00003-4[pii]. 10.1016/j.iac.2009.02.002 [PubMed: 19389580]

De Jong MJ, Chung ML, Wu JR, Riegel B, Rayens MK, Moser DK. Linkages between anxiety and outcomes in heart failure. Heart \& Lung. 2011; 40:393-404. S0147-9563(11)00070-7[pii]. 10.1016/j.hrtlng.2011.02.002 [PubMed: 21453974]

DeMets DL, Califf RM. Lessons learned from recent cardiovascular clinical trials: Part II. Circulation. 2002; 106:880-886. [PubMed: 12176964]

Dickstein K, Cohen-Solal A, Filippatos G, McMurray JJ, Ponikowski P, Poole-Wilson PA, Zamorano JL. ESC Guidelines for the diagnosis and treatment of acute and chronic heart failure 2008: The Task Force for the Diagnosis and Treatment of Acute and Chronic Heart Failure 2008 of the European Society of Cardiology. Developed in collaboration with the Heart Failure Association of the ESC (HFA) and endorsed by the European Society of Intensive Care Medicine (ESICM). European Heart Journal. 2008; 29:2388-2442. ehn309 [pii]. 10.1093/eurheartj/ehn309 [PubMed: 18799522]

Doehner W, Anker SD. Uric acid in chronic heart failure. Seminars in Nephrology. 2005; 25:61-66. S0270929504001536 [pii]. [PubMed: 15660337]

Elashof, J. nQuery advisor 6.0 (Version 4.0). Saugus, MA: Statistical Solutions; 2005.

Fontaine KR, Redden DT, Wang C, Westfall AO, Allison DB. Years of life lost due to obesity. JAMA. 2003; 289:187-193. [PubMed: 12517229]

Frasure-Smith N, Lesperance F, Talajic M. Depression and 18-month prognosis after myocardial infarction. Circulation. 1995; 91:999-1005. [PubMed: 7531624]

Gorkin L, Norvell NK, Rosen RC, Charles E, Shumaker SA, McIntyre KM. The SOLVD Investigators. Assessment of quality of life as observed from the baseline data of the Studies of 
Left Ventricular Dysfunction (SOLVD) trial quality-of-life substudy. American Journal of Cardiology. 1993; 71:1069-1073. [PubMed: 8475871]

Happ MB, Naylor MD, Roe-Prior P. Factors contributing to rehospitalization of elderly patients with heart failure. Journal of Cardiovascular Nursing. 1997; 11:75-84. [PubMed: 9200021]

Harris WS. The omega-3 index as a risk factor for coronary heart disease. American Journal of Clinical Nutrition. 2008; 87:1997S-2002S. 87/6/1997S [pii]. [PubMed: 18541601]

Harris WS, Von Schacky C. The Omega-3 Index: A new risk factor for death from coronary heart disease? Preventive Medicine. 2004; 39:212-220. [pii]. 10.1016/j.ypmed. 2004.02.030S0091743504000878 [PubMed: 15208005]

Hedayat M, Mahmoudi MJ, Rose NR, Rezaei N. Proinflammatory cytokines in heart failure: Doubleedged swords. Heart Failure Review. 2010; 15:543-562.10.1007/s10741-010-9168-4

Heller AR, Theilen HJ, Koch T. Fish or chips? News in Physiological Science. 2003; 18:50-54.

Heo S, Doering LV, Widener J, Moser DK. Predictors and effect of physical symptom status on health-related quality of life in patients with heart failure. American Journal of Critical Care. 2008; 17:124-132. 17/2/124 [pii]. [PubMed: 18310649]

Heo S, Moser DK, Lennie TA, Zambroski CH, Chung ML. A comparison of health-related quality of life between older adults with heart failure and healthy older adults. Heart \& Lung. 2007; 36:1624. S0147-9563(06)00135-X [pii]. 10.1016/j.hrtlng.2006.06.003 [PubMed: 17234473]

Heo S, Moser DK, Riegel B, Hall LA, Christman N. Testing the psychometric properties of the Minnesota living with heart failure questionnaire. Nursing Research. 2005; 54:265-272. [PubMed: 16027569]

Hershberger RE, Ni H, Nauman DJ, Burgess D, Toy W, Wise K, Everett J. Prospective evaluation of an outpatient heart failure management program. Journal of Cardiac Failure. 2001; 7:64-74. [PubMed: 11264552]

Heymans S, Hirsch E, Anker SD, Aukrust P, Balligand JL, Cohen-Tervaert JW, Shah AM. Inflammation as a therapeutic target in heart failure? A scientific statement from the Translational Research Committee of the Heart Failure Association of the European Society of Cardiology. European Journal of Heart Failure. 2009; 11:119-129. hfn043 [pii]. 10.1093/eurjhf/hfn043 [PubMed: 19168509]

Heyward, WH.; Wangner, DR. Applied body composition assessment. 2. Champaign, IL: Human Kinetics; 2004.

Horowitz CR, Rein SB, Leventhal H. A story of maladies, misconceptions and mishaps: Effective management of heart failure. Social Science \& Medicine. 2004; 58:631-643. S0277953603002326 [pii]. [PubMed: 14652059]

Horwich TB, Fonarow GC, Hamilton MA, MacLellan WR, Woo MA, Tillisch JH. The relationship between obesity and mortality in patients with heart failure. Journal of the American College of Cardiology. 2001; 38:789-795. [PubMed: 11527635]

Hoskins LM, Walton-Moss B, Clark HM, Schroeder MA, Thiel L Sr. Predictors of hospital readmission among the elderly with congestive heart failure. Home Healthcare Nurse. 1999; 17:373-381. [PubMed: 10562014]

Hunt SA, Abraham WT, Chin MH, Feldman AM, Francis GS, Ganiats TG, Yancy CW. 2009 Focused update incorporated into the ACC/AHA 2005 Guidelines for the Diagnosis and Management of Heart Failure in Adults: A report of the American College of Cardiology Foundation/American Heart Association Task Force on Practice Guidelines: Developed in collaboration with the International Society for Heart and Lung Transplantation. Circulation. 2009; 119:e391-e479. CIRCULATIONAHA.109.192065. [pii]. 10.1161/CIRCULATIONAHA.109.192065 [PubMed: 19324966]

Ibrahim W, Lee US, Yeh CC, Szabo J, Bruckner G, Chow CK. Oxidative stress and antioxidant status in mouse liver: Effects of dietary lipid, vitamin E and iron. Journal of Nutrition. 1997; 127:14011406. [PubMed: 9202098]

Jiang W, Alexander J, Christopher E, Kuchibhatla M, Gaulden LH, Cuffe MS, O'Connor CM. Relationship of depression to increased risk of mortality and rehospitalization in patients with congestive heart failure. Archives of Internal Medicine. 2001; 161:1849-1856. [PubMed: 11493126] 
Jurgens CY, Moser DK, Armola R, Carlson B, Sethares K, Riegel B. Symptom clusters of heart failure. Research in Nursing \& Health. 2009; 32:551-560.10.1002/nur.20343 [PubMed: 19650069]

Katz JN, Chang LC, Sangha O, Fossel AH, Bates DW. Can comorbidity be measured by questionnaire rather than medical record review? Medical Care. 1996; 34:73-84. [PubMed: 8551813]

Kell R, Haunstetter A, Dengler TJ, Zugck C, Kubler W, Haass M. Do cytokines enable risk stratification to be improved in NYHA functional class III patients? Comparison with other potential predictors of prognosis. European Heart Journal. 2002; 23:70-78. [PubMed: 11741364]

Krumholz HM, Amatruda J, Smith GL, Mattera JA, Roumanis SA, Radford MJ, Vaccarino V. Randomized trial of an education and support intervention to prevent readmission of patients with heart failure. Journal of the American College of Cardiology. 2002; 39:83-89. [PubMed: 11755291]

Lane D, Carroll D, Ring C, Beevers DG, Lip GY. Mortality and quality of life 12 months after myocardial infarction: Effects of depression and anxiety. Psychosomatic Medicine. 2001; 63:221230. [PubMed: 11292269]

Lee CS, Moser DK, Lennie TA, Riegel B. Event-free survival in adults with heart failure who engage in self-care management. Heart \& Lung. 2010; 40:12-20. S0147-9563(09)00320-3[pii]. 10.1016/ j.hrtlng.2009.12.003 [PubMed: 20561885]

Lee CS, Riegel B, Driscoll A, Suwanno J, Moser DK, Lennie TA, Worrall-Carter L. Gender differences in heart failure self-care: A multinational cross-sectional study. International Journal of Nursing Studies. 2009; 46:1485-1495. S0020-7489(09)00144-8[pii]. 10.1016/j.ijnurstu. 2009.04.004 [PubMed: 19442974]

Lennie TA. Anorexia in response to acute illness. Heart \& Lung. 1999; 28:386-401. [PubMed: 10580213]

Lennie TA. Nutritional recommendations for patients with heart failure. Journal of Cardiovascular Nursing. 2006; 21:261-268. [PubMed: 16823278]

Lennie TA, Chung ML, Habash DL, Moser DK. Dietary fat intake and proinflammatory cytokine levels in patients with heart failure. Journal of Cardiac Failure. 2005; 11:613-618. S1071-9164(05)00682-2[pii]. 10.1016/j.card-fail.2005.06.434 [PubMed: 16230265]

Lennie TA, Moser DK, Habash DL. Low sodium diet: Nutritional adequacy and factors limiting adherence. Journal of Cardiac Failure. 2003; 9(Supplement):S5.

Lennie TA, Song EK, Wu JR, Chung ML, Dunbar SB, Pressler SJ, Moser DK. Three gram sodium intake is associated with longer event-free survival only in patients with advanced heart failure. Journal of Cardiac Failure. 2011; 17:325-330. S1071-9164(10)01228-5[pii]. 10.1016/j.cardfail. 2010.11.008 [PubMed: 21440871]

Lesperance F, Frasure-Smith N, Talajic M, Bourassa MG. Five-year risk of cardiac mortality in relation to initial severity and one-year changes in depression symptoms after myocardial infarction. Circulation. 2002; 105:1049-1053. [PubMed: 11877353]

Lindenfeld J, Albert NM, Boehmer JP, Collins SP, Ezekowitz JA, Givertz MM, Walsh MN. HFSA 2010 Comprehensive Heart Failure Practice Guideline. Journal of Cardiac Failure. 2010; 16:e1e194. S1071-9164(10)00173-9[pii]. 10.1016/j.cardfail.2010.04.004 [PubMed: 20610207]

Lloyd-Jones D, Adams RJ, Brown TM, Carnethon M, Dai S, De Simone G, Wylie-Rosett J. Heart disease and stroke statistics-2010 update: A report from the American Heart Association. Circulation. 2010; 121:e46-e215. CIRCULATIONAHA.109.192667. [pii]. 10.1161/ CIRCULATIONAHA.109.192667 [PubMed: 20019324]

Mann, DL. Activation of inflammatory mediators in heart failure. In: Mann, DL., editor. Heart failure. Philadelphia: Saunders; 2004. p. 159-180.

Michalsen A, Konig G, Thimme W. Preventable causative factors leading to hospital admission with decompensated heart failure. Heart. 1998; 80:437-441. [PubMed: 9930040]

Middel B, Bouma J, de Jongste M, van Sonderen E, Niemeijer MG, Crijns H, van den Heuvel W. Psychometric properties of the Minnesota Living with Heart Failure Questionnaire (MLHF-Q). Clinical Rehabilitation. 2001; 15:489-500. [PubMed: 11594639]

Mills RM Jr, Haught WH. Evaluation of heart failure patients: Objective parameters to assess functional capacity. Clinical Cardiology. 1996; 19:455-460. [PubMed: 8790948] 
Moser DK, Doering LV, Chung ML. Vulnerabilities of patients recovering from an exacerbation of chronic heart failure. American Heart Journal. 2005; 150:984. S0002-8703(05)00756-8[pii]. 10.1016/j.ahj.2005.07.028 [PubMed: 16290979]

Moser DK, Frazier SK, Worrall-Carter L, Biddle MJ, Chung ML, Lee KS, Lennie TA. Symptom variability, not severity, predicts rehospitalization and mortality in patients with heart failure. European Journal of Cardiovascular Nursing. 2010; 10:124-129. S1474-5151(10)00074-5[pii]. 10.1016/j.ejcnurse.2010.05.006 [PubMed: 20637697]

Moser DK, Stevenson WG, Woo MA, Stevenson LW. Timing of sudden death in patients with heart failure. Journal of the American College of Cardiology. 1994; 24:963-967. [PubMed: 7930231]

Moser DK, Yamokoski L, Sun JL, Conway GA, Hartman KA, Graziano JA, Stevenson LW. Improvement in health-related quality of life after hospitalization predicts event-free survival in patients with advanced heart failure. Journal of Cardiac Failure. 2009; 15:763-769. [PubMed: 19879462]

Naylor MD. Comprehensive discharge planning for the elderly. Research in Nursing \& Health. 1990; 13:327-347. [PubMed: 2122498]

Opasich C, Febo O, Riccardi PG, Traversi E, Forni G, Pinna G, Tavazzi L. Concomitant factors of decompensation in chronic heart failure. American Journal of Cardiology. 1996; 78:354-357. [PubMed: 8759821]

Packer M, Cohn JN. on behalf of the Steering Committee and Membership of the Advisory Council to Improve Outcomes Nationwide in Heart Failure. Consensus recommendations for the management of chronic heart failure. American Journal of Cardiology. 1999; 83(Supplement 1):2A-38A.

Pennathur S, Maitra D, Byun J, Sliskovic I, Abdulhamid I, Saed GM, Abu-Soud HM. Potent antioxidative activity of lycopene: A potential role in scavenging hypochlorous acid. Free Radical Biology and Medicine. 2010; 49:205-213. S0891-5849(10)00221-2[pii]. 10.1016/j.freeradbiomed. 2010.04.003 [PubMed: 20388538]

Polidori MC, Pratico D, Savino K, Rokach J, Stahl W, Mecocci P. Increased F2 isoprostane plasma levels in patients with congestive heart failure are correlated with antioxidant status and disease severity. Journal of Cardiac Failure. 2004; 10:334-338. S1071916403008005 [pii]. [PubMed: 15309701]

Polidori MC, Savino K, Alunni G, Freddio M, Senin U, Sies H, Mecocci P. Plasma lipophilic antioxidants and malondialdehyde in congestive heart failure patients: Relationship to disease severity. Free Radical Biology and Medicine. 2002; 32:148-152. S0891584901007821 [pii]. [PubMed: 11796203]

Quittan M, Wiesinger GF, Crevenna R, Nuhr MJ, Posch M, Hulsmann M, Fialka-Moser V. Crosscultural adaptation of the Minnesota Living with Heart Failure Questionnaire for German-speaking patients. Journal of Rehabilitation Medicine. 2001; 33:182-186. [PubMed: 11506217]

Rao AV, Ray MR, Rao LG. Lycopene. Advances in Food and Nutrition Research. 2006; 51:99-164. S1043-4526(06)51002-2[pii]. 10.1016/S1043-4526(06)51002-2 [PubMed: 17011475]

Rao LG, Guns E, Rao AV. Lycopene: Its role in health and disease. AGROFood Industry and Hi-Tech (July/August). 2003; 14:25-30.

Rauchhaus M, Doehner W, Francis DP, Davos C, Kemp M, Liebenthal C, Anker SD. Plasma cytokine parameters and mortality in patients with chronic heart failure. Circulation. 2000; 102:3060-3067. [PubMed: 11120695]

Rector TS, Cohn JN. Assessment of patient outcome with the Minnesota Living with Heart Failure questionnaire: Reliability and validity during a randomized, double-blind, placebo-controlled trial of pimobendan. American Heart Journal. 1992; 124:1017-1025. [PubMed: 1529875]

Rector TS, Johnson G, Dunkman WB, Daniels G, Farrell L, Henrick A, Cohn JN. Evaluation by patients with heart failure of the effects of enalapril compared with hydralazine plus isosorbide dinitrate on quality of life. V-HeFT II. The V-HeFT VA Cooperative Studies Group. Circulation. 1993; 87(6 Suppl):VI71-VI77. [PubMed: 8500243]

Rector TS, Kubo SH, Cohn JN. Patients' self-assessment of their congestive heart failure. Heart Failure. 1987; 3:198-209. 
Rector TS, Kubo SH, Cohn JN. Validity of the Minnesota Living with Heart Failure questionnaire as a measure of therapeutic response to enalapril or placebo. American Journal of Cardiology. 1993; 71:1106-1107. [PubMed: 8475878]

Rector TS, Tschumperlin LK, Kubo SH, Bank AJ, Francis GS, McDonald KM, Silver MA. Use of the Living With Heart Failure questionnaire to ascertain patients' perspectives on improvement in quality of life versus risk of drug-induced death. Journal of Cardiac Failure. 1995; 1:201-206. [PubMed: 9420652]

Riegel B, Moser DK, Anker SD, Appel LJ, Dunbar SB, Grady KL, Whellan DJ. State of the science: Promoting self-care in persons with heart failure: A scientific statement from the American Heart Association. Circulation. 2009; 120:1141-1163. CIRCULATIO-NAHA.109.192628. [pii]. 10.1161/CIRCULATIO-NAHA.109.192628 [PubMed: 19720935]

Riegel B, Moser DK, Glaser D, Carlson B, Deaton C, Armola R, Albert N. The Minnesota Living With Heart Failure Questionnaire: Sensitivity to differences and responsiveness to intervention intensity in a clinical population. Nursing Research. 2002; 51:209-218. [PubMed: 12131233]

Rogowski O, Shnizer S, Wolff R, Lewis BS, Amir O. Increased serum levels of oxidative stress are associated with hospital readmissions due to acute heart failure. Cardiology. 2011; 118:33-37. 000324192 [pii]. 10.1159/000324192 [PubMed: 21411994]

Schiff GD, Fung S, Speroff T, McNutt RA. Decompensated heart failure: Symptoms, patterns of onset, and contributing factors. American Journal of Medicine. 2003; 114:625-630. S0002934303001323 [pii]. [PubMed: 12798449]

Schoenfeld DA. Sample-size formula for the proportional-hazards regression model. Biometrics. 1983; 39:499-503. [PubMed: 6354290]

Sheahan SL, Fields B. Sodium dietary restriction, knowledge, beliefs, and decision-making behavior of older females. Journal of the American Academy of Nurse Practitioners. 2008; 20:217-224. JAAN307 [pii]. 10.1111/j.1745-7599.2008.00307.x [PubMed: 18387019]

Shi J, Le Maguer M. Lycopene in tomatoes: Chemical and physical properties affected by food processing. Critical Reviews in Food Science Nutrition. 2000a; 40:1-42. [PubMed: 10674200]

Shi J, Le Maguer M. Lycopene in tomatoes: Chemical and physical properties affected by food processing. Critical Reviews in Biotechnology. 2000b; 20:293334.10.1080/07388550091144212 [PubMed: 11192026]

Silver MA. Dietary research in heart failure: Beyond the salt shaker. Journal of the American College of Cardiology. 2003; 42:1224-1225. [PubMed: 14522485]

Steer RA, Ball R, Ranieri WF, Beck AT. Dimensions of the Beck Depression Inventory-II in clinically depressed outpatients. Journal of Clinical Psychology. 1999; 55:117-128. [PubMed: 10100838]

Steer RA, Clark DA, Beck AT, Ranieri WF. Common and specific dimensions of self-reported anxiety and depression: The BDI-II versus the BDI-IA. Behavior Research Therapy. 1999; 37:183-190.

Stein PK, Carney RM, Freedland KE, Skala JA, Jaffe AS, Kleiger RE, Rottman JN. Severe depression is associated with markedly reduced heart rate variability in patients with stable coronary heart disease. Journal of Psychosomatic Research. 2000; 48:493-500. [PubMed: 10880671]

Stumpf C, Lehner C, Yilmaz A, Daniel WG, Garlichs CD. Decrease of serum levels of the antiinflammatory cytokine interleukin-10 in patients with advanced chronic heart failure. Clinical Science (London). 2003; 105:45-50.

Szabo J, Ibrahim WH, Sunvold GD, Bruckner GG. Effect of dietary protein quality and essential fatty acids on fatty acid composition in the liver and adipose tissue after rapid weight loss in overweight cats. American Journal of Veterinary Research. 2003; 64:310-315. [PubMed: 12661871]

Tavazzi L, Maggioni AP, Marchioli R, Barlera S, Franzosi MG, Latini R, Tognoni G. Effect of n-3 polyunsaturated fatty acids in patients with chronic heart failure (the GISSI-HF trial): A randomised, double-blind, placebo-controlled trial. Lancet. 2008; 372:1223-1230. S0140-6736(08)61239-8[pii]. 10.1016/S0140-6736(08)61239-8 [PubMed: 18757090]

Tsuyuki RT, McKelvie RS, Arnold JM, Avezum A Jr, Barretto AC, Carvalho AC, Yusuf S. Acute precipitants of congestive heart failure exacerbations. Archives of Internal Medicine. 2001; 161:2337-2342. [PubMed: 11606149] 
van der Wal MH, Jaarsma T, Moser DK, van Gilst WH, van Veldhuisen DJ. Unraveling the mechanisms for heart failure patients' beliefs about compliance. Heart \& Lung. 2007; 36:253261. S0147-9563(06)00288-3[pii]. 10.1016/j.hrtlng.2006.10.007 [PubMed: 17628194]

van der Wal MH, Jaarsma T, Moser DK, van Gilst WH, van Veldhuisen DJ. Qualitative examination of compliance in heart failure patients in The Netherlands. Heart \& Lung. 2010; 39:121-130. S0147-9563(09)00186-1[pii]. 10.1016/j.hrtlng.2009.07.008 [PubMed: 20207272]

van der Wal MH, Jaarsma T, Moser DK, Veeger NJ, van Gilst WH, van Veldhuisen DJ. Compliance in heart failure patients: The importance of knowledge and beliefs. European Heart Journal. 2006; 27:434-440. ehi603 [pii]. 10.1093/eurheartj/ehi603 [PubMed: 16230302]

Vinson JM, Rich MW, Sperry JC, Shah AS, McNamara T. Early readmission of elderly patients with congestive heart failure. Journal of the American Geriatric Society. 1990; 38:1290-1295.

Welsh D, Lennie TA, Marcinek R, Biddle MJ, Abshire D, Bentley B, Moser DK. Low-sodium diet self-management intervention in heart failure: Pilot study results. European Journal of Cardiovascular Nursing. 2012 Epub ahead of print. 10.1177/1474515111435604

Welsh D, Marcinek R, Abshire D, Lennie TA, Biddle M, Bentley B, Moser DK. Theory-based lowsodium diet education for heart failure patients. Home Healthcare Nurse. 2010; 28:432-441. quiz 441-433. 10.1097/NHH.0b013e3181e324e000004045-201007000-00009[pii] [PubMed: 20592543]

Wilson, M-MG.; Morley, JE. Encyclopedia of Nutrition. 2. Oxford, UK: Academic Press; 1999. Nutritional management of geriatric patients.

Wu JR, Moser DK, Chung ML, Lennie TA. Objectively measured, but not self-reported, medication adherence independently predicts event-free survival in patients with heart failure. Journal of Cardiac Failure. 2008a; 14:203-210. S1071-9164(07)01134-7[pii]. 10.1016/j.cardfail. 2007.11.005 [PubMed: 18381183]

Wu JR, Moser DK, Chung ML, Lennie TA. Predictors of medication adherence using a multidimensional adherence model in patients with heart failure. Journal of Cardiac Failure. 2008b; 14:603-614. S1071-9164(08)00078-X [pii]. 10.1016/j.cardfail.2008.02.011 [PubMed: 18722327]

Wu JR, Moser DK, De Jong MJ, Rayens MK, Chung ML, Riegel B, Lennie TA. Defining an evidencebased cutpoint for medication adherence in heart failure. American Heart Journal. 2009; 157:285-291. S0002-8703(08)00832-6[pii]. 10.1016/j.ahj.2008.10.001 [PubMed: 19185635]

Wu JR, Moser DK, Lennie TA, Peden AR, Chen YC, Heo S. Factors influencing medication adherence in patients with heart failure. Heart \& Lung. 2008; 37:8-16. e1. S0147-9563(07)00047-7[pii]. 10.1016/j.hrtlng.2007.02.003 [PubMed: 18206522]

Yamaoka M, Yamaguchi S, Okuyama M, Tomoike H. Anti-inflammatory cytokine profile in human heart failure: Behavior of interleukin-10 in association with tumor necrosis factor-alpha. Japanese Circulation Journal. 1999; 63:951-956. [PubMed: 10614840]

Young AJ, Lowe GM. Antioxidant and prooxidant properties of carotenoids. Archives of Biochemistry and Biophysics. 2001; 385:20-27. [PubMed: 11361018]

Zambroski CH, Moser DK, Bhat G, Ziegler C. Impact of symptom prevalence and symptom burden on quality of life in patients with heart failure. European Journal of Cardiovascular Nursing. 2005; 4:198-206. S1474-5151(05)00034-4[pii]. 10.1016/j.ejcnurse.2005.03.010 [PubMed: 15916924]

Zhao YT, Shao L, Teng LL, Hu B, Luo Y, Yu X, Zhang H. Effects of n-3 poly-unsaturated fatty acid therapy on plasma inflammatory markers and $\mathrm{N}$-terminal pro-brain natriuretic peptide in elderly patients with chronic heart failure. Journal of International Medical Research. 2009; 37:18311841. [PubMed: 20146881] 


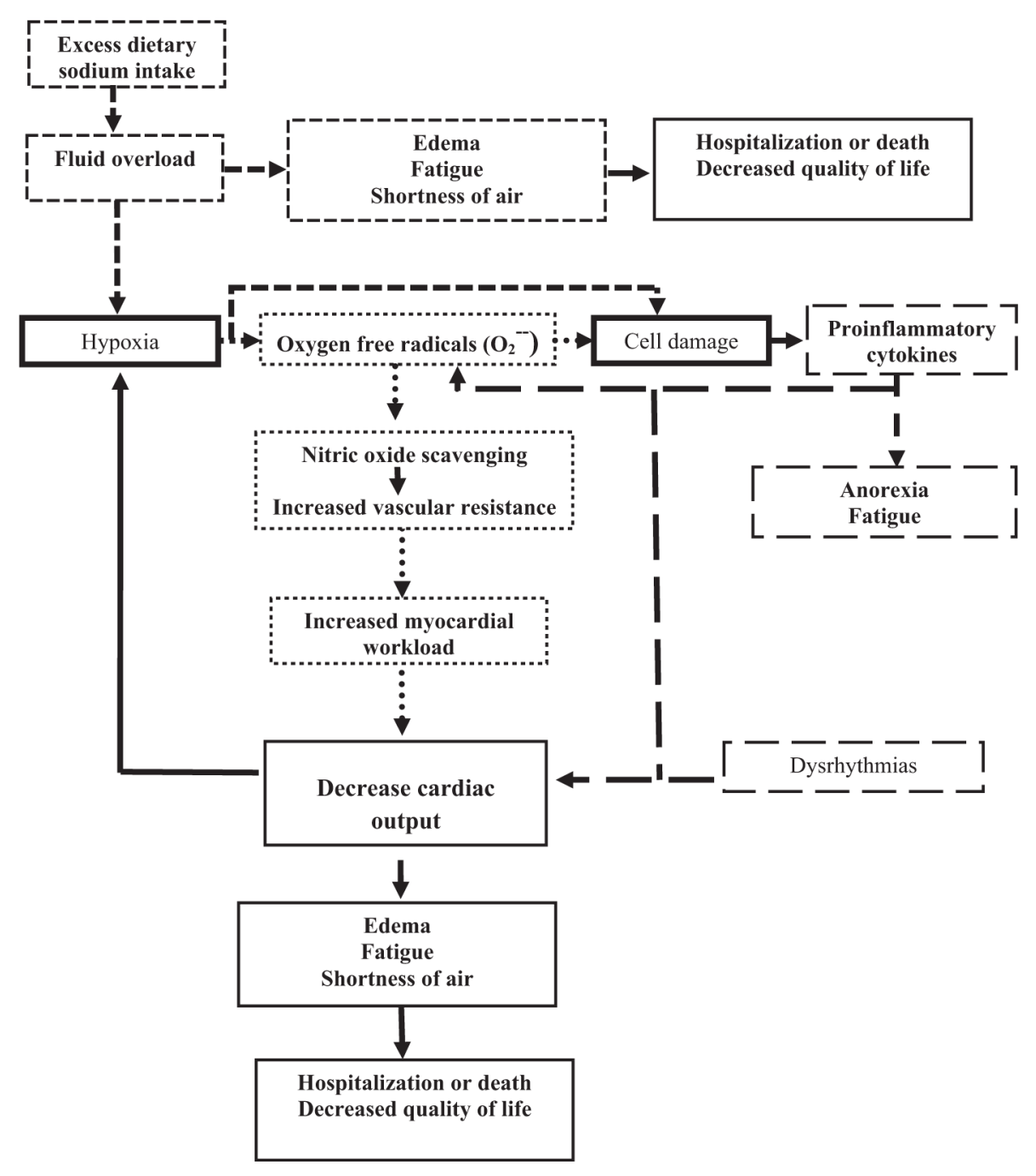

FIGURE 1.

Conceptual framework: The proposed intervention targets three major pathways underlying HF symptoms: fluid overload (depicted by small dashed lines), oxidative stress (dotted lines), and inflammation (large dashed lines). The symptoms produced by these pathways (solid lines) are primary reasons for HF hospitalizations and decreased quality of life (Heo et al., 2007; Hunt et al., 2009). 


\begin{tabular}{|l|l|l|l|l|l|l|l|l|l|l|l|l|l|l|l|l|}
\hline & \multicolumn{3}{|c|}{ YEAR 1 } & \multicolumn{3}{|c|}{ YEAR 2 } & \multicolumn{3}{|c|}{ YEAR 3 } & \multicolumn{3}{|c|}{ YEAR 4 } \\
\hline Quarter & $\mathbf{1}$ & $\mathbf{2}$ & $\mathbf{3}$ & $\mathbf{4}$ & $\mathbf{1}$ & $\mathbf{2}$ & $\mathbf{3}$ & $\mathbf{4}$ & $\mathbf{1}$ & $\mathbf{2}$ & $\mathbf{3}$ & $\mathbf{4}$ & $\mathbf{1}$ & $\mathbf{2}$ & $\mathbf{3}$ & $\mathbf{4}$ \\
\hline $\begin{array}{l}\text { Hire Project Manager. Develop databases, operations } \\
\text { manuals, survey packets. }\end{array}$ & & & & & & & & & & & & & & & & \\
\hline Hire, orient, train staff. Get IRB approval to enroll subjects. & & & & & & & & & & & & & & & & \\
\hline $\begin{array}{l}\text { Enroll sample, collect baseline data, provide intervention, } \\
\text { enter and clean data. }\end{array}$ & & & & & & & & & & & & & & & & \\
\hline Collect follow-up data, enter and clean data. & & & & & & & & & & & & & & & & \\
\hline Finish data entry and cleaning. & & & & & & & & & & & & & & & & \\
\hline Analyze data. & & & & & & & & & & & & & & & \\
\hline Disseminate results. & & & & & & & & & & & & & & & & \\
\hline
\end{tabular}

FIGURE 2.

Estimated timeline for major activities in proposed study. 
Table 1

Quality of Life Scores by Symptom Presence (Higher Score = Worse Quality of Life)

\begin{tabular}{llclrr}
\hline & \multicolumn{2}{l}{ Symptom Present } & & \multicolumn{2}{l}{ Symptom Absent } \\
\cline { 2 - 3 } & Score & $\boldsymbol{n}$ & Score & $\boldsymbol{n}$ \\
\hline Edema & $48 \pm 22$ & 124 & $32 \pm 22$ & 140 \\
Fatigue & $44 \pm 22$ & 225 & $16 \pm 14$ & 38 \\
Shortness of air & $47 \pm 22$ & 175 & $26 \pm 19$ & 88 \\
\hline
\end{tabular}


Table 2

Symptom Frequency by Diet Quality

\begin{tabular}{lcccc}
\hline & Worst Diet, \% $(\boldsymbol{n}=\mathbf{3 3})$ & Poor Diet, \% $(\boldsymbol{n}=\mathbf{1 1 4})$ & Good Diet, \% $(\boldsymbol{n}=\mathbf{8 2})$ & Best Diet, \% $(\boldsymbol{n}=\mathbf{1 9})$ \\
\hline Edema & 58 & 50 & 40 & 42 \\
Fatigue & 94 & 84 & 90 & 63 \\
Shortness of air & 70 & 73 & 63 & 37 \\
\hline
\end{tabular}


Table 3

Quality of Life Scores by Diet Quality (Higher Score = Worse Quality of Life)

\begin{tabular}{lrc}
\hline Diet Quality & $\boldsymbol{n}$ & Quality of Life \\
\hline Worst diet & 33 & $48 \pm 22$ \\
Poor diet & 114 & $40 \pm 23$ \\
Good diet & 82 & $37 \pm 23$ \\
Best diet & 19 & $29 \pm 24$ \\
\hline
\end{tabular}




\section{Table 4}

\section{Dependent Variables and Measurement}

\begin{tabular}{|c|c|c|c|}
\hline Aim & Variable & Instrument & Times Measured \\
\hline \multirow[t]{3}{*}{1} & Symptom burden & Memorial Symptom Assessment Scale-Heart Failure & Baseline, 3, 6, 9, and 12 months \\
\hline & Quality of life & Minnesota Living with Heart Failure Questionnaire & Baseline, 3, 6, 9, and 12 months \\
\hline & $\begin{array}{l}\text { HF hospitalization or all cause } \\
\text { death }\end{array}$ & $\begin{array}{l}\text { Cause of hospitalization and death by monthly patient/family } \\
\text { phone interview and hospital admission/medical record review }\end{array}$ & $3-12$ months \\
\hline \multirow[t]{3}{*}{2} & Dietary sodium intake & 24-hour diet recall interview for 2 weekday and 1 weekend day & Baseline, 3 and 6 months \\
\hline & Oxidative stress & Serum malondialdehyde, PGF2a isoprostane and uric acid & Baseline, 3 , and 6 months \\
\hline & Inflammation & $\begin{array}{l}\text { Serum tumor necrosis factor-a; soluble TNF receptors sTNFR1 } \\
\text { and sTNFR2; interleukin-10. }\end{array}$ & Baseline, 3 , and 6 months \\
\hline 3 & Intervention adherence & $\begin{array}{l}\text { Fluid balance using body weight; plasma lycopene; erythrocyte } \\
\text { omega-3 index }\end{array}$ & Baseline, 3 , and 6 months \\
\hline
\end{tabular}


Table 5

Options for Lycopene Supplementation Component

\begin{tabular}{lclc}
\hline Intervention Group Choices & Lycopene (mg) & Usual Care Group Choices & Lycopene (mg) \\
\hline Low sodium tomato juice (8 oz.) & 20 & $100 \%$ apple juice $(8 \mathrm{oz})$. & 0 \\
Low sodium V8 juice (11.5 oz.) & 24 & $100 \%$ cranberry juice (8 oz.) & 0 \\
Low sodium tomato soup (8 oz.) & 25 & $100 \%$ orange juice & 0 \\
Spaghetti sauce (5 oz.) & 25 & & \\
\hline
\end{tabular}

